\title{
Dynamic soil-structure interaction analyses considering directionality effects
}

Luis A. Pinzón (luis.pinzon@upc.edu) (corresponding author)

Department of Civil and Environmental Engineering

Universitat Politècnica de Catalunya, Barcelona, Spain

ORCID: 0000-0003-3128-7158

Miguel A. Mánica (mmanicam@iingen.unam.mx)

Instituto de Ingeniería

Universidad Nacional Autónoma de México, Ciudad de México, México

ORCID: 0000-0002-0520-6951

Luis G. Pujades (lluis.pujades@upc.edu)

Department of Civil and Environmental Engineering

Universitat Politècnica de Catalunya, Barcelona, Spain

ORCID: 0000-0002-2619-0805

Rodrigo E. Alva (rodrigo.esteban.alva@upc.edu)

Department of Civil and Environmental Engineering

Universitat Politècnica de Catalunya, Barcelona, Spain

ORCID: 0000-0002-4522-3967

\section{Keywords}

Soil-structure interaction; directionality effects; steel frame buildings; intensity measures; nonlinear dynamic analysis 


\begin{abstract}
The paper investigates directionality effects of ground motions in the context of dynamic soilstructure interaction (DSSI) analyses. The problem addressed corresponds to a nonlinear soil deposit, overlaying firm ground, where the input motion was derived from an acceleration time history recorded at a rock outcrop. A simplified procedure is proposed to incorporate directionality effects. The main objective is to identify in advance the incidence angle producing the maximum response of a structure for a given earthquake. Results from the simplified procedure were evaluated by comparison with what is called here the complete rotational approach, where the behaviour of the structure, as a function of the incidence angle of the input motion, is derived through a large number of nonlinear dynamic soil-structure interaction analyses. The obtained results show the importance of considering directionality effects in DSSI analyses. The maximum response of the system was reasonably captured with the simplified approach.
\end{abstract}

\title{
1. Introduction
}

Earthquake ground-motions are recorded in three orthogonal components: two horizontal (normally N-S and E-W) and one vertical. These as-recorded time histories are usually employed to derive input motions for dynamic analyses [1-3]. However, the intensity of ground motions is not uniform in all directions. In the case of as-recorded accelerograms, their intensity will depend on the orientation of the sensor. Such orientation rarely corresponds to the direction in which maximum intensities occur and, therefore, the maximum response of a given system generally takes place for an intermediate unknown angle. This dependence on orientation is commonly known as directionality effect of ground motions.

Over the past two decades, directionality effects have received considerable attention. Research has been performed to assess these effects on recorded ground motions [4,5], intensity measures 
and their influences on the development of ground motion prediction equations [6-9], seismic demands of buildings [10-16], probabilistic damage assessment [17], directivity effects in nearfault regions [18-20], horizontal-to-vertical spectral ratios [21-23], seismic risk assessment of highways [24], and the performance of bridge foundations [25].

As shown in $[10,11,16]$, directionality effects can be addressed in time-history-based dynamic analyses by using a number of linear combinations of the two horizontal as-recorded components as input motions. In this way, peak response parameters can be determined as functions of the rotation angle. This method is called here the complete rotational approach (CRA). However, dynamic analyses are generally computationally expensive, especially when nonlinear behaviour is considered. For this reason, some simplified approaches have been developed to incorporate directionality effects without the need of performing a large number of analyses $[11,26]$. For instance, a spectral matching technique was employed by Pinzón et al. [11] to derive input motions accounting for directionality. However, in most of these studies, directionality effects are taken into account in the seismic performance of buildings without considering the soil-structure interaction.

Let us consider the case of a dynamic soil-structure interaction analysis (DSSI), where a soil deposit (nonlinear) exists resting on firm ground (bedrock), and the input motion was derived from a ground motion recorded at a rock outcrop. In this case, directionality cannot be addressed directly in the input motion since site effects modify the response [27]. The angle where the maximum response of the structure occurs varies significantly from that estimated from the input motion applying simplified procedures. Certainly, directionality effects could be addressed applying the CRA; however, DSSI analyses are by far more computationally expensive compared to structural dynamic analyses preventing the use of the CRA in most cases. 
In this paper, a simplified alternative is evaluated to incorporate directionality effects in DSSI by means of finite element (FE) analyses. The main objective is to identify in advance the angle that produces the maximum response of the soil-structure system for a given seismic action and, therefore, to perform only one DSSI analysis. Site effects are incorporated through free-field simulations, where the CRA is applied; free-field simulations are quite inexpensive compared to full DSSI analyses. The assumption explored is that the incidence angle that generates the maximum value of an intensity measure (IM), at the top of the soil deposit (free-field), will cause the maximum response of the structure. The IMs explored are: (1) the peak ground acceleration and peak ground velocity (PGA and PGV), (2) the PGV/PGA ratio, (3) the Arias intensity (AI), (4) the specific energy density (SED), (5) the cumulative absolute velocity (CAV), the angle that makes the response spectrum closest to RotD100 (i.e. the RotI100 spectrum as defined by Boore [28]), and (7) the spectral response for the fundamental period of the structure (SATf). RotD100 and RotI100 are orientation-independent intensity measures, proposed by Boore [8], based on the spectral response of the rotated horizontal components. These intensity measures eliminate the effect of the sensor orientation as a component of epistemic uncertainty. Here, Rot refers to rotation, D and I means period-dependent and -independent respectively, and 100 refers to the $100^{\text {th }}$ percentile of the rotated spectra (more details on these IMs are described in section 4.2.5). These IMs were selected since they are commonly employed, both in the development of seismic hazard studies [29], and in the estimation of the expected damage of structures (e.g. correlations of these IMs with the Damage Index and Inter-storey Drift Ratios [30], and with the Seismic Indices of Destructiveness [20]). Results from the simplified procedure were evaluated by comparison with the CRA. In addition, the effect of different seismic actions, thicknesses of the soil deposit and the number of storeys were evaluated. 


\section{Case study}

A sketch of the problem addressed is depicted in Fig. 1, where the input motion, applied at the base of the FE model, is derived from an acceleration time history recorded at a rock outcrop; situations where the available accelerograms were recorded on top of the soil deposit are not considered here. The different incidence angles are obtained from the linear combination of the two horizontal asrecorded components of the considered acceleration time histories, by performing a usual coordinate transformation. The structure considered is a steel frame building rigidly connected to a concrete raft foundation. The soil deposit corresponds to a medium to dense sandy layer overlying a bedrock. Analyses were performed using the FE code PLAXIS 2D [31], where the soil was characterised using an elastoplastic constitutive model. Details regarding the input motion, the surface structure, and the FE model are given in the following sections.

In the base case, a $30 \mathrm{~m}$ thick soil deposit was considered since the average shear wave velocity over the top $30 \mathrm{~m}\left(V_{s 30}\right)$ is a commonly used parameter for site classification in seismic codes $[32,33]$. The influence of parameters such as the soil layer thickness, the input motions, and the number of storeys were also studied in this research. Three different groups of analyses were considered (see Table 1). In the first group, the $30 \mathrm{~m}$ thick soil and three different acceleration records were employed. In the second, the soil layer thickness was varied, and values of 10, 20, and $30 \mathrm{~m}$ were considered; one of the seismic actions of the first group was used here. Finally, in the third group, the analyses were performed with buildings of 3, 4 and 5 storeys using the same seismic action as the one used in the second group analyses.

\subsection{Input motions}

Input motions were derived from horizontal as-recorded components of the Friuli (1976), Campania (1980), and Umbria (1997) earthquakes in Italy. The recording stations are all located 
on rock outcrops, which are assumed to correspond to the bedrock underlying the soil deposit. The ground motion records and site specifications were obtained from the European Strong-Motion database [34]. In this work, ground motions were selected considering only their capacity to excite significantly the soil-structure system. For more specific cases, for which the specific site is known, site-specific ground motions should be used according to the seismic hazard of the area.

Fig. 2 shows the acceleration time histories of the two horizontal components of the selected accelerograms. The Friuli earthquake ground motion was recorded at the TLM1 station on May 6, 1976. The earthquake had a moment magnitude $\left(\mathrm{M}_{\mathrm{w}}\right)$ of 6.5 and a recorded PGA of $350 \mathrm{~cm} / \mathrm{s}^{2}$ (obtained from the as-recorded components). The Campania earthquake $\left(\mathrm{M}_{\mathrm{w}}=6.9\right)$ was recorded at the STR station (November 23, 1980) and registered a PGA of $316.8 \mathrm{~cm} / \mathrm{s}^{2}$. Finally, the Umbria earthquake was recorded at the NCR station on September 26, 1997 with $\mathrm{M}_{\mathrm{w}}=6.0$ and a PGA of $745.4 \mathrm{~cm} / \mathrm{s}^{2}$

On the other hand, ground motion accelerations show great variability in time and space. For instance, if we ignore the vertical component, this variation takes place only on the horizontal plane. Then, the maximum acceleration will generally occur at an orientation that is different from those observed in the as-recorded accelerograms. These features can be observed in Fig. 3, where the acceleration hodogram for the two horizontal accelerograms recorded at TLM1 station, after the Friuli earthquake, is depicted. The true PGA is $463.3 \mathrm{~cm} / \mathrm{s}^{2}$ and occurs at an azimuth of $319^{\circ}$. For Campania and Umbria records, the true PGA are 326.6 and $834.4 \mathrm{~cm} / \mathrm{s}^{2}$ respectively.

Thus, in order to account for different incidence angles, rotated input motions, $a_{1}^{\prime}(t, \theta)$ and $a_{2}^{\prime}(t, \theta)$, were derived from linear combinations of the two horizontal as-recorded components, $a_{1}(t)$ and $a_{2}(t)$, as a function of the rotation angle $\theta$ :

$$
a_{1}^{\prime}(t, \theta)=a_{1}(t) \cos \theta+a_{2}(t) \sin \theta
$$




$$
a_{2}^{\prime}(t, \theta)=-a_{1}(t) \sin \theta+a_{2}(t) \cos \theta
$$

where $t$ is the time. Pairs of $a_{1}^{\prime}$ and $a_{2}^{\prime}$ represent different relative orientations between the ground motion and the considered structure. However, as only two-dimensional analyses are being considered in this work, only one of the rotated components is employed to derive the input motions for the analyses. Therefore, iteration in the range of $0-180^{\circ}$ degrees is required to consider all possible, no redundant, actions in the analysed frame.

\subsection{Surface structure}

As mentioned before, the considered surface structures consist of a 2-, 3- and 4-storey steel frame buildings founded on a $0.30 \mathrm{~m}$ thick concrete raft foundation. The columns and beams are assumed to correspond to American wide-flange sections W16x89 and W14x68 respectively [35]. These sections have been modelled through 2D plate-type elements, with three degrees of freedom per node (two translational and one rotational) that follow Mindlin's theory [36]. The behaviour of all structural elements was assumed linear elastic and the connections between them are fully restrained [37]. Dimensions of the 4-storey building model are shown in Fig. 4a. The dimensions of the 3- and 5-storey buildings are the same, only removing and adding a storey respectively. The weight of the structure, including architectural finishes and facilities, were considered as dead loads. Live loads magnitudes were selected according to ASCE7-10 [38] provisions for office use. $100 \%$ of dead loads and $25 \%$ of live loads have been considered as inertial mass in the dynamic analyses [38]. To account for energy dissipation in the structural elements, Rayleigh damping was included with $\alpha$ and $\beta$ coefficients selected to obtain a $\%$ damping ratio in the fundamental period of the structure; a 2\% damping ratio is generally recommended for steel frame buildings [39]. Note 
that the employed structures have been calibrated with the 3D model used by Pinzón et al. [11] to achieve equivalent dynamic performance.

\subsection{Main features of the finite element model}

As mentioned before, the soil deposit is characterised as a $30 \mathrm{~m}$ thick medium to dense sandy layer, with a deep water table, overlaying a bedrock; thicknesses of 20 and $10 \mathrm{~m}$ were also considered. The full soil-structure system was modelled in the FE code PLAXIS 2D [31], assuming plane strain conditions. The FE mesh and main boundary conditions (for the $30 \mathrm{~m}$ thick soil deposit) are depicted in Fig. 4b. The mesh comprises 4225 triangular 15-noded finite elements with fourthorder interpolation and 12 integration points. The mesh is more refined in the $70 \mathrm{~m}$ long zone directly under the building, where the soil-structure interaction (SSI) phenomenon mainly takes place. The latter was verified by comparing the obtained surface response from the free field simulation and from those considering the building. The lateral extension of the model was considered large enough so that any unwanted wave reflections are damped before reaching the zone where the SSI effects are relevant. Absorbing boundaries were also considered to account for the semi-infinite nature of the ground. For the lateral faces, free-field boundaries were employed. They consist of one-dimensional elements (for 2D problems) where the free-field response is computed. They are coupled to the main grid through viscous dashpots, which apply normal and shear stresses to account for the difference between the movement of the main grid (at the boundary) and the free-field elements. At the bottom face, a compliant base was prescribed [40] based on the use of independent dashpots in the normal and shear directions. They provide adequate means to absorb waves approaching the boundary. Both free-field and compliant boundary conditions are succinctly described in [31]. 
Since negligible modifications of the outcrop motions occur by their deconvolution through the rock to the desired elevation, the original accelerograms recorded at rocky outcrops were directly employed to derive input motions at the base of the FE models [41]. However, since a compliant base was prescribed at this boundary, absorbing the downward propagating waves, only the upward component of the motions must be applied. This is obtained by taking half of the outcrop motions. In addition, since an acceleration history (or velocity, or displacement) would nullify the absorbing effect of the compliant base, the input motion is given in terms of a shear stress time history, computed as:

$$
\tau=2 \rho V_{\mathrm{s}} \dot{u}_{x}^{\mathrm{u}}
$$

where $\rho$ is the density, $V_{s}$ is the shear wave velocity, and $\dot{u}_{x}^{u}$ is the horizontal particle velocity of the upward propagating motion. The factor of two is added because half of the stress is absorbed by the viscous dashpots.

The Plaxis Hardening Soil model with small-strain stiffness was employed to account for the nonlinear response of the soil [31]. The model is formulated within the framework of elastoplasticity and includes features like small-strain stiffness degradation, a hyperbolic hardening law, a volumetric yield cap, and a Mohr-Coulomb type limit surface. A detailed description of the model can be found in $[31,42,43]$. Employed parameters are shown in Table 2. They were chosen to represent a medium to dense sand deposit. Energy dissipation occurs in the model due to both small-strain stiffness degradation and plastic strains. However, for small strain amplitudes, damping is generally underestimated [42]. Therefore, Rayleigh damping was also included in the soil elements, with $\alpha$ and $\beta$ coefficients selected to obtain a $2 \%$ damping ratio at the fundamental vibration period of the soil deposit. The small layer considered for the bedrock (Fig. 4b), required to apply the proper input motion, was characterised as a linear elastic material. 
After stress initialisation, a static phase was considered where the building and its foundation were activated. Then, the dynamic analyses described in this work were performed.

\section{Complete rotational approach - CRA}

As mentioned before, directionality effects can be studied in DSSI analyses by performing simulations with a number of linear combinations of the two horizontal acceleration components of the input motion (Eq. (1)) (the vertical component is generally neglected). Increments of $1^{\circ}$ are usually employed, in the range of $0^{\circ}$ and $180^{\circ}$. Then, the distribution of any output variable can be plotted as a function of the incidence angle allowing the determination of the most critical orientation for the system. However, this method entails high computational costs, and it would be of practical interest to develop a simplified approach to assess directionality effects with fewer computational resources.

In this work, the CRA approach was applied to all considered cases to serve as a benchmark to evaluate the results of the simplified procedure. For each case analysed, 90 2D DSSI analyses (using increments of $2^{\circ}$ ) were performed resulting in 630 analyses. The main monitored variable was the horizontal roof displacement relative to the base of the building. This demand parameter can be related to the level of structural damage [11].

Results obtained for the different cases are shown in Fig. 5 as maximum relative roof displacement values. In the first group of analyses (Fig. 5a), results using different input motions are compared. The seismic motions of the Friuli earthquake resulted in the largest displacements and showed the largest difference between maximum and minimum values as functions of the incidence angle. It is also important to notice that the variation with orientation is quite different for each seismic action and, therefore, unconservative designs might result from using the asrecorded components depending on the selected ground motion. 
In the second group of analyses (Fig. 5b), motions of the Friuli earthquake are also employed in combination with layer thicknesses of 10 and $20 \mathrm{~m}$. Although the shape of the variation is somewhat similar for the different cases, the maximum relative roof displacements occur at different orientations for each of them even though the same input motion is being employed. This result stresses the fact that directionality effects cannot be addressed directly in the input motion in the presence of soil deposits.

Finally, in the third group (Fig. 5c), analyses were performed using the seismic action from Friuli, but considering 3- and 5-storey buildings as surface structures. Again, the variation with orientation differs significantly among the different analyses since the dynamic response of each model depends on the dynamic properties of the structure. The 4-storey building resulted in the largest displacements although, depending on the incidence angle, larger displacements can occur in the 5-storey building. Nevertheless, note that, unlike the 3-storey building, the location of the maxima is well defined for the 4- and 5-storey buildings, and the angles where the maxima occur are relatively similar.

Results shown in Fig. 5 were obtained from approximately 3000 hours of computing time on Intel Core i7-4712HQ 2.67 GHz CPUs; certainly, an excessive amount of time for conventional engineering projects.

\section{Simplified rotational approach - SRA}

A simplified approach is pursued here for the prediction of the incidence angle producing the peak response of a soil-structure system. By deriving this angle in advance, only one DSSI analysis is required for a given seismic action compared to the large number of analyses involved in the CRA. The assumption explored is that the angle that generates the maximum value of an intensity measure, at the top of the soil deposit (free-field motion), would also cause the maximum response 
of the structure. The motion at the surface is obtained through free-field site response analyses, where the CRA is applied; in this way, site effects are introduced. Then, IMs, as functions of the rotation angle, can be determined from the motion computed at the surface of the soil deposit and from which the critical orientation between the seismic action and the soil-structure-system may be predicted.

\subsection{Free-field seismic actions computations}

The application of the CRA to the free-field response implies conducting site response analyses for each rotation angle considered. They are usually performed using frequency-domain methodologies, to reduce calculation times, where nonlinearity is introduced through iterative procedures [44]. However, the elastoplastic constitutive law employed here prevents the use of frequency-domain approaches. The free-field response is addressed here through dynamic FE analyses. However, they demand much fewer computational resources compared to full DSSI analyses since only a slender column of soil, with special boundary conditions, is required [2].

The geometry and mesh of the free-field FE model (for the $30 \mathrm{~m}$ thick soil deposit) are depicted in Fig. 6. This model shares most of the features of the full DSSI model (Fig. 4b) except for the lateral boundary conditions, where tied degrees of freedom were employed. With these conditions, the nodes of the left and right boundaries at the same elevation are connected so that they are characterised by the same vertical and horizontal displacements [45].

In Fig. 7, the acceleration records of the as-recorded components (E-W $\theta=0^{\circ}$, N-S $\left.\theta=90^{\circ}\right)$ and the rotated component for $\theta=50^{\circ}$ of the Friuli earthquake are compared with the results of the freefield simulations at the surface. Clearly, an amplification of the signal occurs in the three cases due to site effects. This amplification is also evident in the response spectra (Fig. 8), where considerably larger spectral ordinates are obtained from the free-field simulations. 


\subsection{Intensity measures}

From the free-field time histories at the surface, the angles that produce the maximum value of each IM are identified. The IMs explored are: (1) the peak ground acceleration and velocity, (2) the PGV/PGA ratio, (3) the Arias intensity, (4) the specific energy density, (5) the cumulative absolute velocity, (6) the angle that corresponds to the RotI100 response spectrum, and (7) the spectral response for the fundamental period of the building. Then, the obtained orientations can be compared with those from the CRA to assess the performance of each IM.

In the following sections, the determination of the critical angle, for each IM, is described. Only results for the first group of analyses (different seismic actions) are shown. However, the obtained results for different soil layer thicknesses (second group of analyses) and different number of storeys (third group of analyses) are also compared with the CRA later on (see Table 4).

\subsubsection{Peak ground acceleration, peak ground velocity, and PGV/PGA ratio}

For a given time, the magnitude of acceleration or velocity components of a recorded motion depends on the considered incidence angle $\theta$. Therefore, peak values can be determined as a function of $\theta$ as follow:

$$
\begin{aligned}
& \operatorname{PGA}_{\text {rot }}(\theta)=\max \left[\left|a c c_{\text {rot }}(t, \theta)\right|\right]_{\text {for } t} \text { for } \theta \epsilon[0180] \\
& \operatorname{PGV}_{\text {rot }}(\theta)=\max \left[\mid \text { vel }_{\text {rot }}(t, \theta) \mid\right]_{\text {for } t} \text { for } \theta \epsilon\left[\begin{array}{ll}
0 & 180]
\end{array}\right.
\end{aligned}
$$

where $a c c_{\text {rot }}$ and $v e l_{\text {rot }}$ are the rotated acceleration and velocity time histories of the horizontal components. Fig. 9 shows the variation of $\mathrm{PGA}_{\text {rot }}$ and $\mathrm{PGV}_{\text {rot }}$ (normalised by the maximum value) for the three ground motions considered; locations of the maxima are indicated with circles in the 
figure. The variations of these two IMs are significantly different, but their maximum values occur at somewhat similar orientations.

Tso et al. [46] use the PGV/PGA ratio as a measure of the frequency content of an earthquake ground motion. Sucuoglu and Nurtug [47] correlated this ratio to the seismic energy dissipation since it is linked to the duration of the dominant acceleration pulse of a near-fault impulsive motion. Bommer et al. [48] used this ratio to estimate corner periods at which the constant acceleration ends and the constant displacement begins on code spectra. For each rotation angle, the PGV/PGA ratio can be defined as:

$$
\operatorname{PGV}_{\text {rot }}(\theta) / \mathrm{PGA}_{\text {rot }}(\theta)=\frac{\max \left[\left|v e l_{\text {rot }}(t, \theta)\right|\right]_{\text {for } t}}{\max \left[\left|a c c_{\text {rot }}(t, \theta)\right|\right]_{\text {for } t}} \text { for } \theta \epsilon[0180]
$$

The variation of this IM is shown in Fig. 10. The angles that generate the maximum normalised ratios are $2^{\circ}, 42^{\circ}$ and $126^{\circ}$ for the Friuli, Campania, and Umbria seismic actions respectively. Note that the problem has a periodicity of $180^{\circ}$ and, therefore, results for angles close to $0^{\circ}$ are, in fact, similar to those close to $180^{\circ}$. Consequently, similar orientations are obtained compared to Fig. 9 even though the shapes of the curves are quite different.

\subsubsection{Arias intensity - AI}

The AI is a measure of the severity of a ground motion defined as the total energy per unit weight stored by a set of undamped simple oscillators at the end of a strong seismic action due to an earthquake [49]. The AI, for a given rotated motion, is computed in the following way:

$$
\mathrm{AI}_{\operatorname{rot}}(\theta)=\frac{\pi}{2 g} \int_{0}^{t_{f}} a c c_{\operatorname{rot}}(t, \theta)^{2} d t
$$

where $g$ is the acceleration due to gravity and $t_{f}$ is the total duration of the record. The variation of $\mathrm{AI}$ as a function $\theta$ is shown in Fig. 11. The angles producing the maximum value for this IM for 
the first group of analyses are $164^{\circ}, 44^{\circ}$ and $104^{\circ}$ for the Friuli, Campania, and Umbria earthquakes respectively.

\subsubsection{Specific energy density - SED}

The SED $[50,51]$ is defined as the integral of the squared velocity time history $v e l_{\text {rot }}$ for the total duration of the motion $t_{f}$ (Eq. (8)); therefore, this IM is, to some extent, analogous to the AI (Eq. (7)).

$$
\operatorname{SED}_{\operatorname{rot}}(\theta)=\int_{0}^{t_{f}} v e l_{\text {rot }}(t, \theta)^{2} d t
$$

In Fig. 12, the variation of the SED, as a function of the rotation angle, is shown. For the first group of analyses, the angles where the maxima $\mathrm{SED}_{\text {rot }}$ occur are $162^{\circ}, 14^{\circ}$ and $104^{\circ}$ for the seismic actions of Friuli, Campania and Umbria earthquakes respectively.

\subsubsection{Cumulative absolute velocity - CAV}

The CAV is an IM proposed by Reed and Kassawara [52], and it has been used to estimate the destructive potential of strong ground motions. It is defined in the following way:

$$
\operatorname{CAV}_{\text {rot }}(\theta)=\int_{0}^{t_{f}}\left|a c c_{\text {rot }}(t, \theta)\right| d t
$$

The normalised CAV, as a function of $\theta$ is shown in Fig. 13. The angles where the maximum value is achieved are $164^{\circ}, 52^{\circ}$ and $128^{\circ}$ for the accelerograms recorded during the Friuli, Campania and Umbria earthquakes, respectively. 


\subsubsection{Maximum spectral response}

The aim is to find the angle that generates spectral accelerations closest to the RotD100 spectrum within a given range of vibration periods; the range considered is related to the fundamental period of the system. The response spectrum, for a given $\theta$, is estimated using Eq. (10). The RotD100 spectrum is the envelope of all spectra from the rotated motions (Fig. 14b and Fig. 14d).

$$
\mathrm{SA}_{\text {rot }}(T, \xi, \theta)=\max \left(\left|\ddot{u}_{\text {rot }}(t, T, \xi, \theta)\right|\right)_{\text {for } t}
$$

where $\mathrm{SA}_{\text {rot }}$ is a spectral acceleration from a rotated motion, $\ddot{u}_{\text {rot }}$ is the acceleration response of a single-degree-of-freedom damped oscillator, $T$ is the vibration period, and $\xi$ is the damping ratio. A penalty function is computed as follows:

$$
\operatorname{penalty}(\theta)=\frac{1}{N_{\text {per }}} \sum_{i=1}^{N_{\text {per }}}\left[\frac{\mathrm{SA}_{\text {rot }}(T i, \xi, \theta)}{\operatorname{SA}_{\operatorname{RotD} 100}(T i, \xi)}-1\right]^{2}
$$

where $\mathrm{SA}_{\mathrm{RotD} 100}$ are the spectral ordinates of the RotD100 spectrum, and $N_{\text {per }}$ is the number of sample period between $T_{1}$ and $T_{2}$. Then, the RotI100T $T_{2} T_{2}$ spectrum is defined as the one obtained from the rotated motion that minimises the penalty function. This orientation is assumed as the critical $\theta$ for this IM.

In Fig. 14, an example of the determination of the RotI100 $\mathrm{T}_{1} \mathrm{~T}_{2}$ spectrum, using strong motion data from Friuli earthquake, is presented. Fig. 14a and Fig. 14b show the results obtained for a wide range of periods (between 0.0 and $2.0 \mathrm{~s}$ ). The studied building has a predominant period of $0.95 \mathrm{~s}$ and, therefore, a range between 0.9 and $1.0 \mathrm{~s}$ has also been considered to calculate the RotI100T $_{1} \mathrm{~T}_{2}$ spectrum. The obtained results are shown in Fig. 14c and Fig. 14d. Note that the critical angle varies considerably depending on the period range considered. In this study, a range of $\pm 0.05 \mathrm{~s}$ of the predominant period of the buildings was used. 


\subsubsection{Spectral response for the fundamental period of the building - SATf}

An IM highly used in both seismic hazard studies and structural analyses is the spectral response at the building's fundamental period. This measure is defined as the maximum acceleration response of a 5\% damped single-degree-of-freedom linear oscillator, as shown in the following equation:

$$
S A_{\mathrm{Tf}(\mathrm{rot})}(T f, \xi, \theta)=\max \left(\left|\ddot{u}_{\text {rot }}(t, T f, \xi, \theta)\right|\right)_{\text {for } t}
$$

In fact, this approach coincides with that of section 4.2 .5 if the period range is reduced to a single value. The variation of this IM is shown in Fig. 15 for the considered seismic actions. For the Friuli earthquake, the critical angle is $0^{\circ}$ (or $180^{\circ}$ ), which is the same result obtained in Fig. 14c.

\section{CRA and SRA comparison}

In this section, the critical angles predicted with the SRA are compared with the CRA. Fig. 16 shows the relative roof displacement, as a function of the rotation angle, obtained through the CRA for the group of analyses 1 (30 m soil layer and different input motions); the position of the maximum values is indicated with a black square. The values obtained with the SRA, for the different IMs, are also indicated in the figure with red circles. For the Friuli earthquake, the SRA captured reasonably the angle where the maximum response of the building occurs (in terms of relative roof displacements) with all the IMs (recall that the $180^{\circ}$ periodicity implies that angles close to $180^{\circ}$ are also close to $0^{\circ}$ ). For the other two earthquakes, a larger dispersion is observed between the different IMs. The PGV and the PGV/PGA ratio predicted the angles closest to the CRA for the three earthquakes considered. The obtained critical orientations from all the analyses performed are summarised in Table 3 . In the second group of analyses (different soil thickness and Friuli seismic actions), the PGV and PGV/PGA ratio also showed the closest values to the CRA. 
Finally, in the third group of analyses (different buildings and Friuli seismic actions), the RotI100T $\mathrm{T}_{2}$ IM produced, on average, the closest values to the CRA, followed by the PGV and the PGV/PGA ratio respectively. Results are coherent since RotI100T $1 \mathrm{~T}_{2}$ takes into account the variation of the structure (structural behaviour) using the maximum spectral response in a range of period close to the fundamental period of each building.

The maximum displacements obtained through the CRA and SRA are compared in Table 4; the relative error with respect to the CRA approach is also indicated (a negative sign implies an underestimation of the relative roof displacement). The lowest mean error (averaged over all the considered cases) was obtained with the PGV (-2.476\%), which is also the IM capturing the closest critical angle (see Table 3). The PGV/PGA ratio, the RotI100T $1 \mathrm{~T}_{2}$ and the AI also achieved similar error magnitudes. Nevertheless, the latter shows larger differences with respect to the critical angle (Table 3). The worst performing IM was the SATf, with a mean relative error of $-11.892 \%$.

Although the SRA is not able to predict exactly neither the critical angle nor the maximum relative roof displacement obtained with the CRA, the errors are much smaller compared to those obtained using the as-recorded components (Table 5), which is the customary practice. The mean errors obtained using the E-W and the N-S components for all analysed cases are $-10.334 \%$ and $25.353 \%$ respectively. When the recorded motion is polarised with one of the horizontal principal directions of the accelerometer, the errors would be small. This situation occurred in the E-W component of the Friuli earthquake seismic actions, where a relative error of $-2.475 \%$ (4-storey case) and $-2.222 \%$ (5-storey case) were estimated. However, this is generally not the case and the relative roof displacements can be underestimated as much as $50 \%$ if directionality effects are not properly addressed. 


\section{Conclusions}

In this study, the importance of considering directionality effects of ground motions in 2D DSSI analyses has been highlighted. Two-dimensional models are widely used to perform DSSI analyses, since they are less computationally expensive than a three-dimensional (3D) one [5357]. On the other hand, an important deficiency in DSSI analyses, usually performed, is that only the as-recorded components of ground motions are adopted, without considering other angles that could lead to a more severe structural response. These effects can be addressed by analysing the considered problem with a number of linear combinations of the input motions for different incidence angles. Then, the orientation producing the maximum response of the structure can be determined; this procedure was termed here the CRA. It was found that, if directionality effects are overlooked and only the as-recorded components are employed to derive the input motions for the analyses, the building response (in terms of relative roof displacements) can be underestimated as much as $50 \%$.

On the other hand, DSSI analyses are computationally expensive preventing the use of the CRA in most cases. In addition, already established simplified procedures to incorporate directionality effects for structural analyses cannot be employed directly to the input motions for DSSI analyses since site effects tend to modify the response. A simplified procedure has been proposed here to identify, in advance, the angle that produces the maximum response of a structure for a given seismic action and, therefore, to perform only one DSSI analysis. Site effects are incorporated by applying the CRA to free-field site response simulations, since they are quite inexpensive compared to full DSSI analyses. Then, the critical orientation is predicted from the maximum value of a given IM, as a function of the rotation angle, from the motions computed at the surface of the free-field simulations. Different IMs were evaluated, and the PGV resulted in critical angles and relative roof displacements closest to the CRA. Although the exact values were 
not predicted, the mean relative differences with respect to the CRA, in terms of roof displacements, were only $-2.476 \%$ (mean value of the considered cases); much smaller than those obtained using the as-recorded directions.

The proposed simplified approach, using the PGV as IM, appears to be an attractive and economical alternative to incorporate directionality effects in DSSI analyses. The high computational cost of DSSI analyses, where the soil is characterised with an elastoplastic constitutive model, prevents the use of a large number of earthquake records. Three acceleration pairs, leading to 630 nonlinear dynamic analyses, have been considered adequate for the purpose of the paper, i.e. to propose a simplified approach to predict the worst angle orientation, thus avoiding such large number of costly dynamic analyses. Nevertheless, the procedure must be further validated under different conditions, such as different characteristics of the soil deposit, additional seismic actions corresponding to different kinds of earthquakes, and, of course, different surface structures. In addition, future analyses should be performed considering 3D models and the non-linearity properties and damage of the structure.

Although the effects of directionality should always be considered for earthquake-resistant design and assessment, it is important to mention that using the most unfavourable incidence angle, in each of the selected ground-motion records, could lead to over-conservative results. The specific way in which directionality must be considered for design is not discussed in this work and deserves further research. Nonetheless, the proposed approach, to economically determine the most unfavourable orientation in DSSI analyses, might serve as a tool for such kind of studies.

\section{Acknowledgements}

This research was partially funded by the Spanish Ministry of Economy and Competitiveness and by the European Regional Development Fund through the project CGL2015-65913-P. The first 
author was supported by a PhD scholarship from the Institute for Training and Development of Human Resources of Panama and the National Secretariat for Science, Technology and Innovation of Panama. The fourth author was supported by a PhD scholarship from the National Council for Science and Technology of Mexico.

\section{References}

[1] Mánica Malcom MÁ, Ovando-Shelley E, Botero Jaramillo E. Numerical study of the seismic behavior of rigid inclusions in soft Mexico City Clay. J Earthq Eng 2016;20:44775. doi:10.1080/13632469.2015.1085462.

[2] Mánica M, Ovando E, Botero E. Assessment of damping models in FLAC. Comput Geotech 2014;59:12-20. doi:10.1016/j.compgeo.2014.02.007.

[3] Carbonari S, Dezi F, Leoni G. Linear soil-structure interaction of coupled wall-frame structures on pile foundations. Soil Dyn Earthq Eng 2011;31:1296-309. doi:10.1016/j.soildyn.2011.05.008.

[4] Bradley BA, Baker JW. Ground motion directionality in the 2010-2011 Canterbury earthquakes. Earthq Eng Struct Dyn 2015;44:371-84. doi:10.1002/eqe.2474.

[5] Pinzón LA, Pujades LG, Diaz SA, Alva RE. Do Directionality Effects Influence Expected Damage? A Case Study of the 2017 Central Mexico Earthquake. Bull Seismol Soc Am 2018;108:2543-55. doi:10.1785/0120180049.

[6] Shahi SK, Baker JW. NGA-West2 models for ground motion directionality. Earthq Spectra 2014;30:1285-300. doi:10.1193/040913EQS097M.

[7] Boore DM, Watson-Lamprey JA, Abrahamson NA. Orientation-Independent Measures of Ground Motion. Bull Seismol Soc Am 2006;96:1502-11. doi:10.1785/0120050209.

[8] Boore DM. Orientation-Independent, Nongeometric-Mean Measures of Seismic Intensity 
from Two Horizontal Components of Motion. Bull Seismol Soc Am 2010;100:1830-5. doi:10.1785/0120090400.

[9] Pinzón LA, Pujades LG, Hidalgo-Leiva DA, Diaz SA. Directionality models from ground motions of Italy. Ing Sismica 2018;35:43-63.

[10] Rigato AB, Medina RA. Influence of angle of incidence on seismic demands for inelastic single-storey structures subjected to bi-directional ground motions. Eng Struct 2007;29:2593-601. doi:10.1016/j.engstruct.2007.01.008.

[11] Pinzón LA, Diaz SA, Pujades LG, Vargas YF. An efficient method for considering the directionality effect of earthquakes on structures. J Earthq Eng 2019;in-press:1-30. doi:10.1080/13632469.2019.1597783.

[12] Fujii K. Assessment of pushover-based method to a building with bidirectional setback. Earthq Struct 2016;11:421-43. doi:10.12989/eas.2016.11.3.421.

[13] Athanatopoulou AM. Critical orientation of three correlated seismic components. Eng Struct 2005;27:301-12. doi:10.1016/j.engstruct.2004.10.011.

[14] Kostinakis KG, Manoukas GE, Athanatopoulou AM. Influence of seismic incident angle on response of symmetric in plan buildings. KSCE J Civ Eng 2017;00:1-11. doi:10.1007/s12205-017-1279-1.

[15] Cantagallo C, Camata G, Spacone E. The Effect of the Earthquake Incidence Angle on Seismic Demand of Reinforced Concrete Structures. 15th World Conf. Earthq. Eng. Lisbon Port., 2012.

[16] Lagaros ND. The impact of the earthquake incident angle on the seismic loss estimation. Eng Struct 2010;32:1577-89. doi:10.1016/j.engstruct.2010.02.006.

[17] Vargas-Alzate YF, Pujades LG, Barbat AH, Hurtado JE, Diaz SA, Hidalgo-Leiva DA. Probabilistic seismic damage assessment of reinforced concrete buildings considering 
direccionality effects. Struct Infrastruct Eng 2018;14:817-29.

doi:10.1080/15732479.2017.1385089.

[18] Gordo-Monsó C, Miranda E. Bulletin of Earthquake Engineering Significance of Directivity Effects During the 2011 Lorca Earthquake in Spain 2011. doi:10.1007/s10518017-0301-9.

[19] Huang YN, Whittaker AS, Luco N. Maximum spectral demands in the near-fault region. Earthq Spectra 2008;24:319-41. doi:10.1193/1.2830435.

[20] Garini E, Gazetas G. Damage potential of near-fault records: Sliding displacement against conventional “Intensity Measures.” Bull Earthq Eng 2013;11:455-80. doi:10.1007/s10518012-9397-0.

[21] Matsushima S, Kosaka H, Kawase H. Directionally dependent horizontal-to-vertical spectral ratios of microtremors at Onahama, Fukushima, Japan. Earth, Planets Sp 2017;69. doi:10.1186/s40623-017-0680-9.

[22] Pinzón LA, Pujades LG, Macau A, Carreño E, Alcalde JM. Seismic Site Classification from the Horizontal-to-Vertical Response Spectral Ratios: Use of the Spanish StrongMotion Database. Geosciences 2019;9:294. doi:10.3390/geosciences9070294.

[23] Stanko D, Markušić S, Strelec S, Gazdek M. HVSR analysis of seismic site effects and soil-structure resonance in Varaždin city (North Croatia). Soil Dyn Earthq Eng 2017;92:666-77. doi:10.1016/j.soildyn.2016.10.022.

[24] Torbol M, Shinozuka M. The directionality effect in the seismic risk assessment of highway networks. Struct Infrastruct Eng 2014;10:175-88. doi:10.1080/15732479.2012.716069.

[25] Soltanieh S, Memarpour MM, Kilanehei F. Performance assessment of bridge-soilfoundation system with irregular configuration considering ground motion directionality 
effects. Soil Dyn Earthq Eng 2019;118:19-34. doi:10.1016/j.soildyn.2018.11.006.

[26] Diaz SA, Pujades LG, Pinzón LA, Vargas Y. An alternative approach to consider the effect of seismic directionality. Rev Ing Construcción 2018;33:279-90.

[27] Pinzón LA, Mánica Malcom MÁ, Pujades LG, Alva RE. A simplified approach to account for directionality effects on 2D dynamic soil-structure interaction analysis. In: Silvestri F, Moraci N, editors. Earthq. Geotech. Eng. Prot. Dev. Environ. Constr., Rome, Italy: CRC Press, Taylor \& Francis Group; 2019, p. 4490-7.

[28] Boore DM. Orientation-Independent, Nongeometric-Mean Measures of Seismic Intensity from Two Horizontal Components of Motion. Bull Seismol Soc Am 2010;100:1830-5. doi:10.1785/0120090400.

[29] Baker JW, Bradley BA. Intensity Measure Correlations Observed in the NGA-West2 Database, and Dependence of Correlations on Rupture and Site Parameters. Earthq Spectra 2017;33:145-56. doi:10.1193/060716EQS095M.

[30] Kostinakis KG, Athanatopoulou AM, Morfidis K. Correlation between ground motion intensity measures and seismic damage of 3D R/C buildings. Eng Struct 2015;82:151-67. doi:10.1016/j.engstruct.2014.10.035.

[31] Brinkgreve RBJ, Kumarswamy S, Swolfs WM. PLAXIS 2D 2017.

[32] CEN. European Standard EN 1998-1:2005 Eurocode 8: Design of structures for earthquake resistance. Part 1: General rules, seismic actions and rules for buildings English version. Brussels, Belgium: 2004.

[33] ASCE. Minimum Design Loads and Associated Criteria for Buildings and Other Structures (ASCE/SEI 7-16). 2017. doi:10.1061/9780784414248.

[34] Ambraseys NN, Smit PM, Beradi R, Rinaldis D, Cotton F, Berge C. Dissemination of European Strong-Motion Data, CD ROM collection, European Commission, Directorate- 
General XII, Environmental and Climate Programme, ENV4-CT97-0397. 2000.

[35] ASTM A992 / A992M - 11. Standard Specification for Structural Steel Shapes. 2015.

[36] Mindlin RD. Influence of rotatory inertia and shear flexural motions of isotropic elastic plates. J Appl Mech 1951;18:31-8.

[37] ANSI/AISC 358-10. Prequalified connections for special and intermediate steel moment frames for seismic applications. 2010.

[38] ASCE. Minimum Design Loads for Buildings and Other Structures. 2010. doi:10.1061/9780784412916.

[39] Paz M, Leigh W. Structural Dynamics: Theory And Computation. 2003.

[40] Lysmer J, Kuhlemeyer L. Finite dynamic model for infinite media. J Eng Mech Div $1969 ; 95: 859-78$

[41] Mejia LH, Dawson EM. Earthquake deconvolution for FLAC. Forth iternational FLAC Symp., Madrid: 2006.

[42] Brinkgreve RBJ, Kappert MH, Bonnier PG. Hysteretic damping in a small-strain stiffness model. Proc. Tenth Int. Symp. Numer. Model. Geomech., Rhodes, Greece: Taylor \& Francis; 2007, p. 737-42.

[43] Schanz T, Vermeer PA, Bonnier PG. The hardening soil model: Formulation and verification. Beyond 2000 Comput. Geotech., 1999, p. 16. doi:10.1201/978131513820627.

[44] Schnabel P., Lysmer J, Seed HB. SHAKE: a computer program for earthquake response analysis of horizontally layered sites. Report EERC 72-12, Earthquake Engineering Research Center. Berkeley: 1972.

[45] Zienkiewicz OC, Bicanic N, Shen FQ. Earthquake input definition and the transmitting boundary conditions. In: Doltsinis IS, editor. Adv. Comput. Nonlinear Mech., Vienna: 
International Centre for Mechanical Sciences (Courses and Lectures), Springer; 1988, p. 109-38.

[46] Tso WK, Zhu TJ, Heidebrecht AC. Engineering implication of ground motion A/V ratio. Soil Dyn Earthq Eng 1992;11:133-44.

[47] Sucuoğlu H, Nurtuğ A. Earthquake ground motion characteristics and seismic energy dissipation. Earthq Eng Struct Dyn 1995;24:1195-213. doi:10.1002/eqe.4290240903.

[48] Bommer JJ, Elnashai A-S, Weir AG. Compatible acceleration and displacement spectra for seismic design codes. 12th World Conf. Earthq. Eng., Auckland, New Zealand: 2000, p. paper no. 207.

[49] Arias A. A measure of earthquake intensity. Cambridge, MA, MIT Press 1970:438-83.

[50] Sarma SK. Energy flux of strong earthquakes. Tectonophysics 1971;11:159-72.

[51] Sarma SK, Yang KS. An evaluation of strong motion records and a new parameter A95. Earthq Eng Struct Dyn 1987;15:119-32. doi:10.1002/eqe.4290150109.

[52] Reed JW, Kassawara RP. A criterion for determining exceedance of the Operating Basis Earthquake. Nucl Eng Des 1990;123:387-96.

[53] Kham M, Semblat JF, Bard P-Y, Dangla P. Seismic site-city interaction: Main governing phenomena through simplified numerical models. Bull Seismol Soc Am 2006;96:1934-51. doi: $10.1785 / 0120050143$.

[54] Genes MC, Kocak S. Dynamic soil-structure interaction analysis of layered unbounded media via a coupled finite element/boundary element/scaled boundary finite element model. Int J Numer Methods Eng 2005;62:798-823. doi:10.1002/nme.1212.

[55] Tabatabaiefar HR, Fatahi B, Samali B. Seismic behavior of building frames considering dynamic soil-structure interaction. Int J Geomech 2013;13:409-20. doi:10.1061/(ASCE)GM.1943-5622.0000231. 
[56] Sáez E, Lopez-Caballero F, Modaressi-Farahmand-Razavi A. Inelastic dynamic soilstructure interaction effects on moment-resisting frame buildings. Eng Struct 2013;51:166-77. doi:10.1016/j.engstruct.2013.01.020.

[57] Tabatabaiefar HR, Fatahi B. Idealisation of soil-structure system to determine inelastic seismic response of mid-rise building frames. Soil Dyn Earthq Eng 2014;66:339-51. doi:10.1016/j.soildyn.2014.08.007. 


\section{Figures}

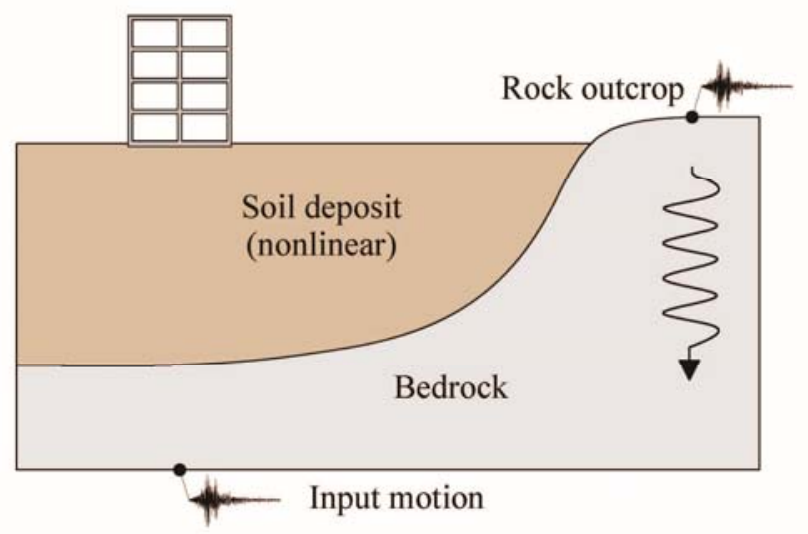

Fig. 1. Input motion for DSSI analyses from an acceleration history recorded at a rock outcrop 
(a)
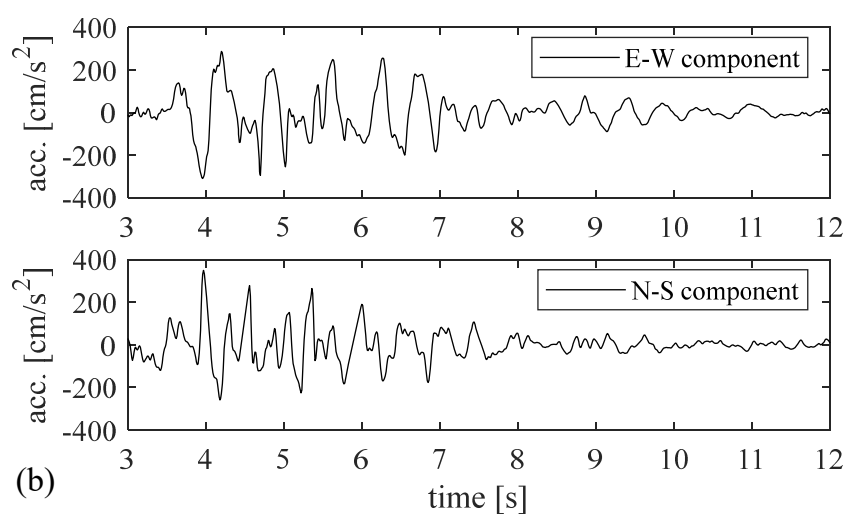

(b)
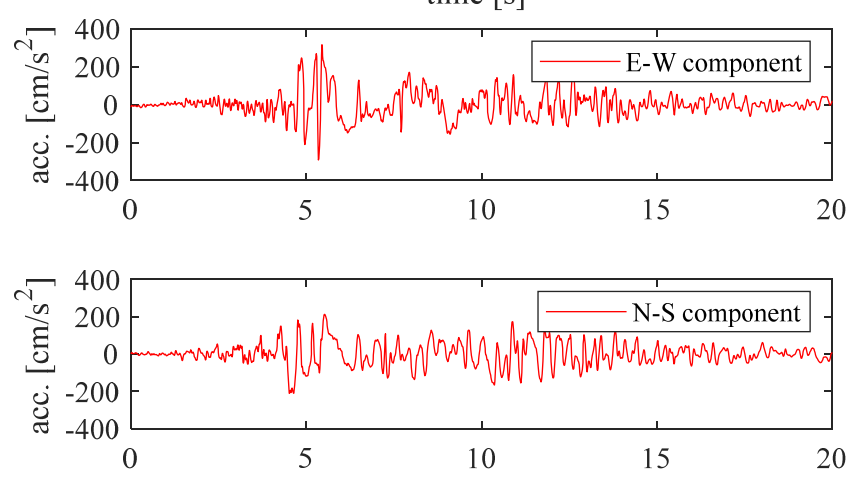

(c) time $[\mathrm{s}]$
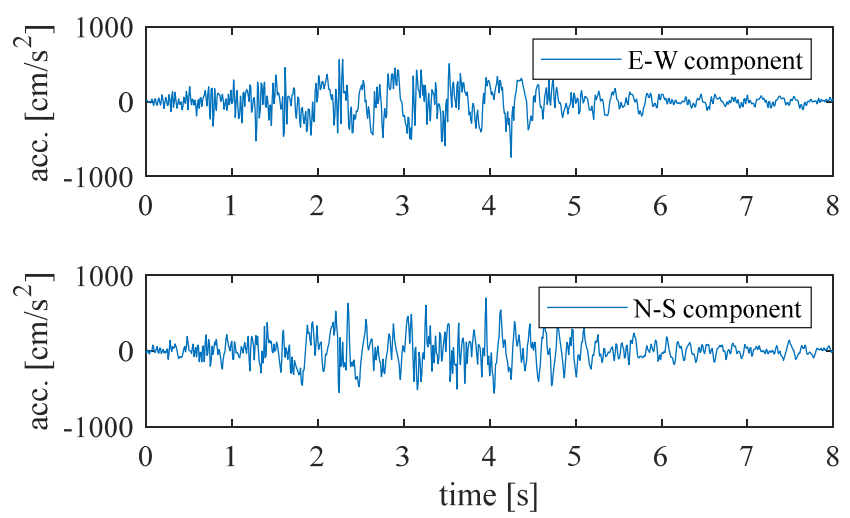

Fig. 2. As recorded ground motion horizontal components of the earthquakes considered: (a) Friuli in 1976, (b) Campania in 1980, and (c) Umbria in 1997 [16]. 


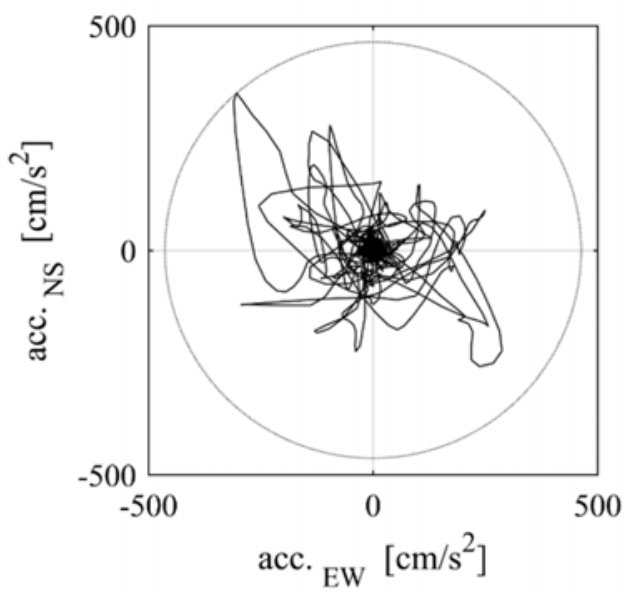

Fig. 3. Particle acceleration motion of the accelerograms of the Friuli earthquake.

(a)

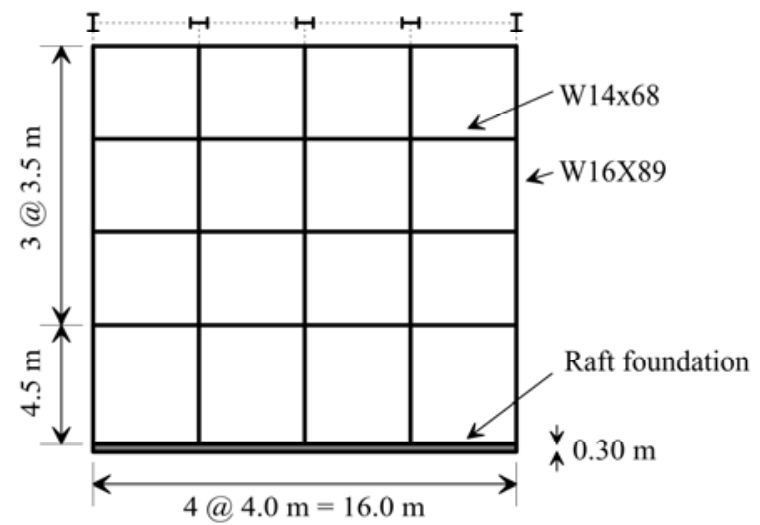

(b)

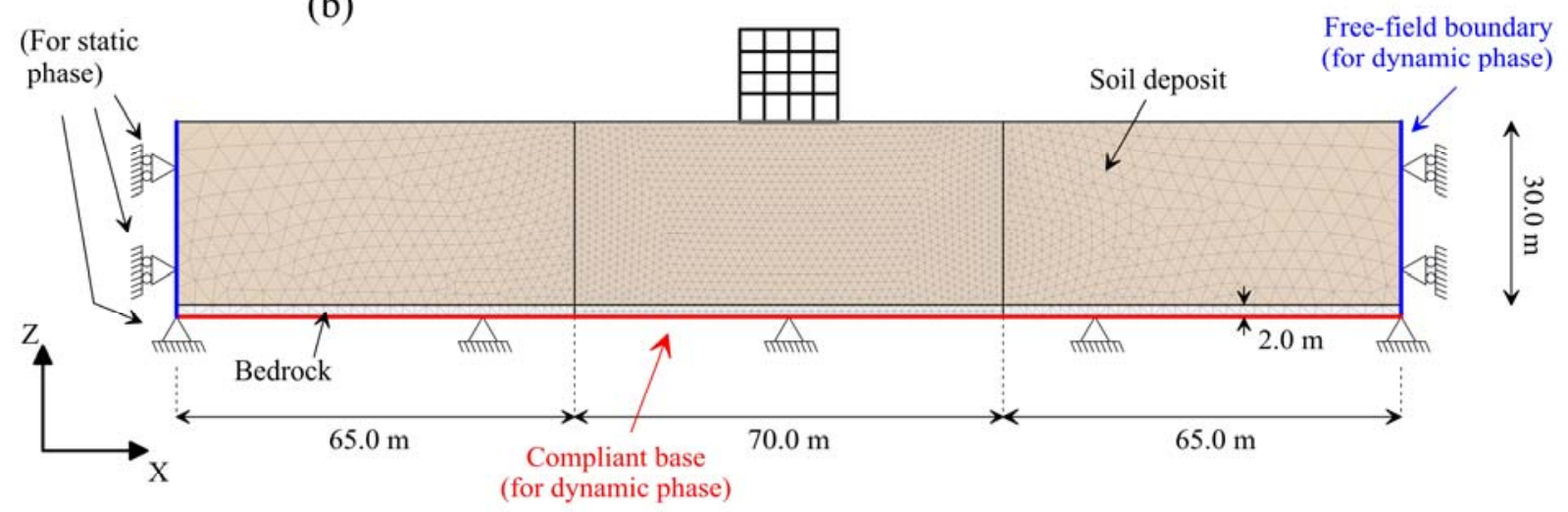

Fig. 4. (a) Building geometry and (b) soil-building FE model employed. 
(a)

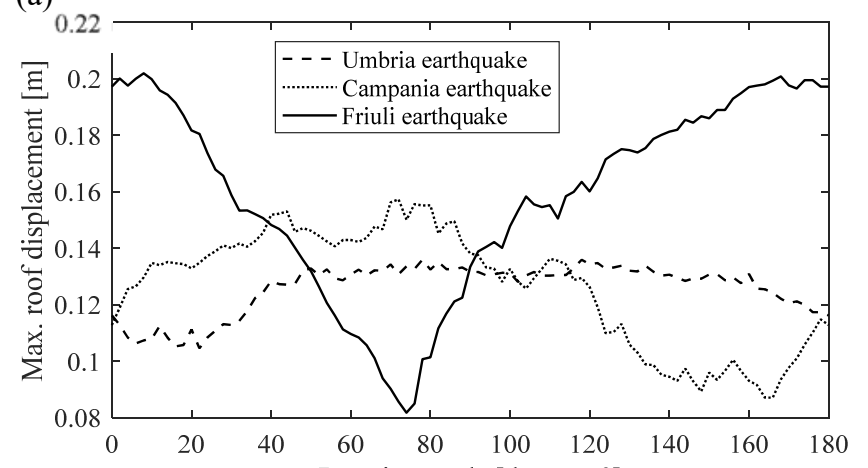

(b)
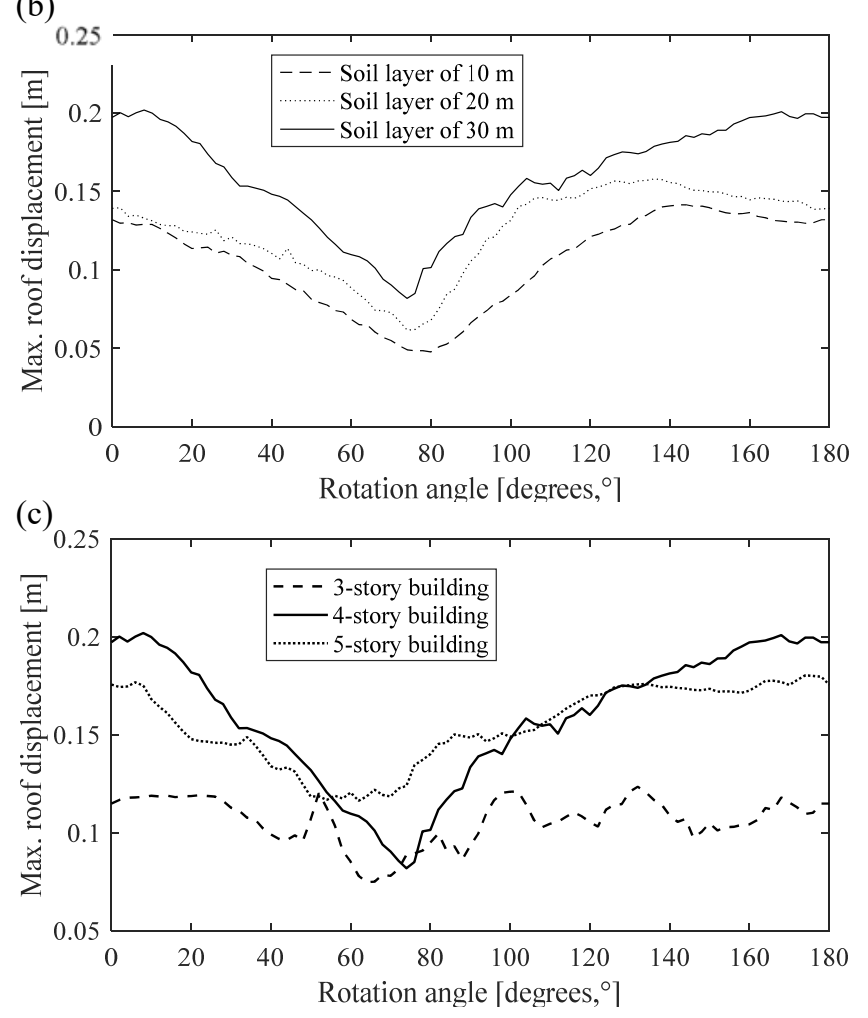

Fig. 5. Maximum relative roof displacement as a function of the rotation angle obtained from the CRA for groups 1 (a), 2 (b) and 3 (c). 


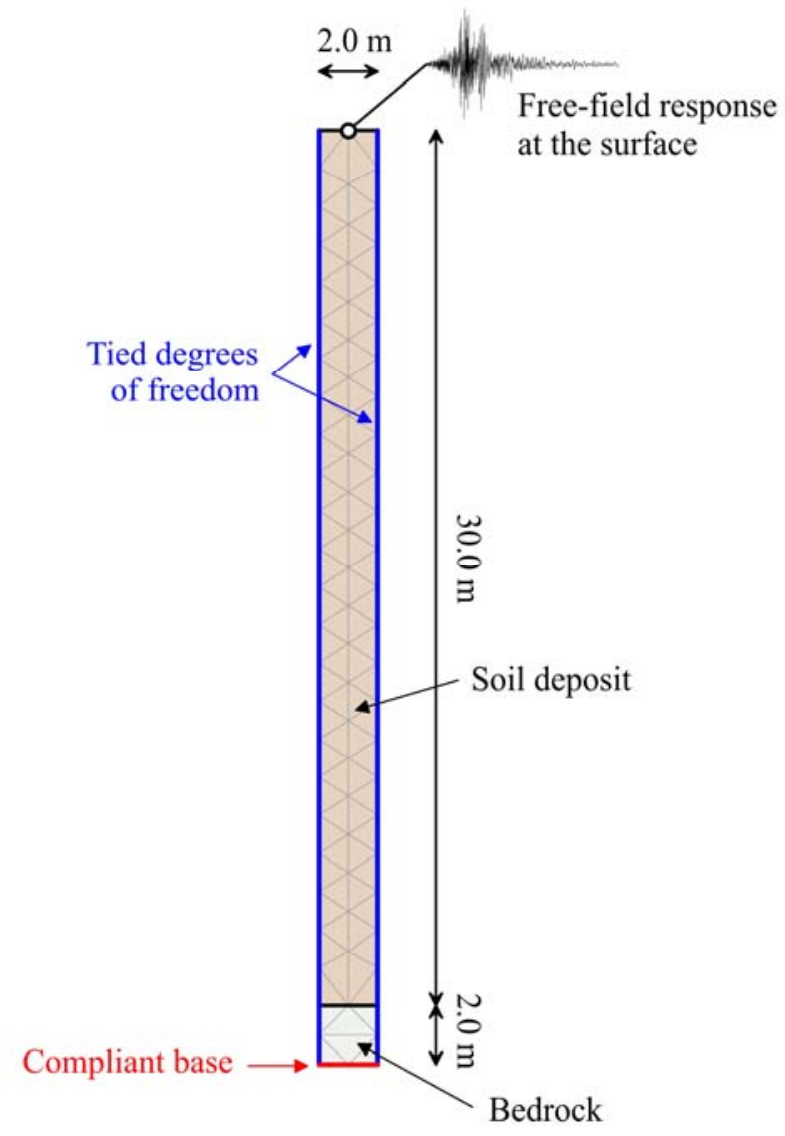

Fig. 6. Geometry, mesh, and boundary conditions of the free-field FE simulation 


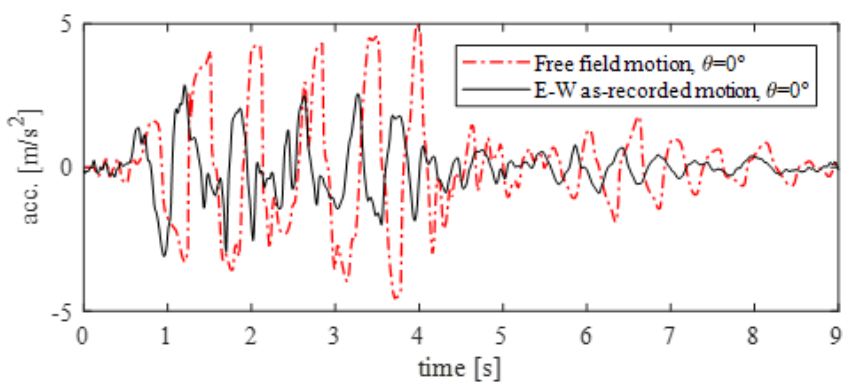

(a)

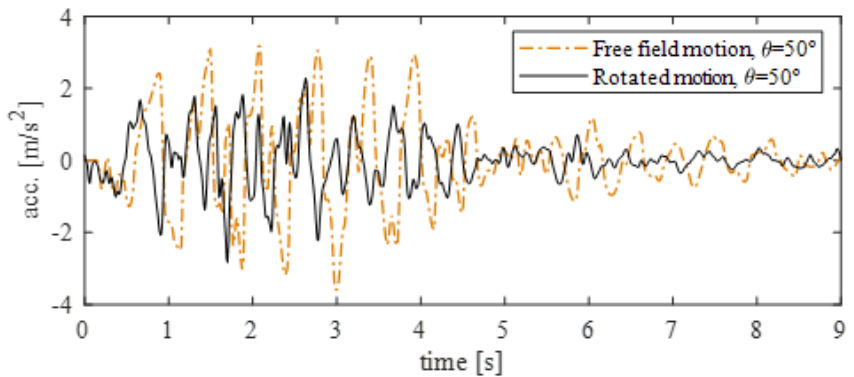

(b)

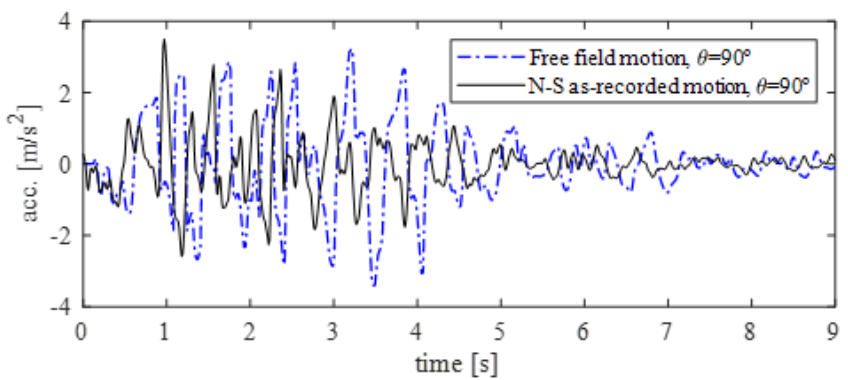

(c)

Fig. 7. Time histories from the recorded motion and the free-field motion at the Surface for the accelerograms of the Friuli earthquake. Rotation angles of (a) $\theta=0^{\circ}$, (b) $\theta=50^{\circ}$, and (c) $\theta=90^{\circ}$

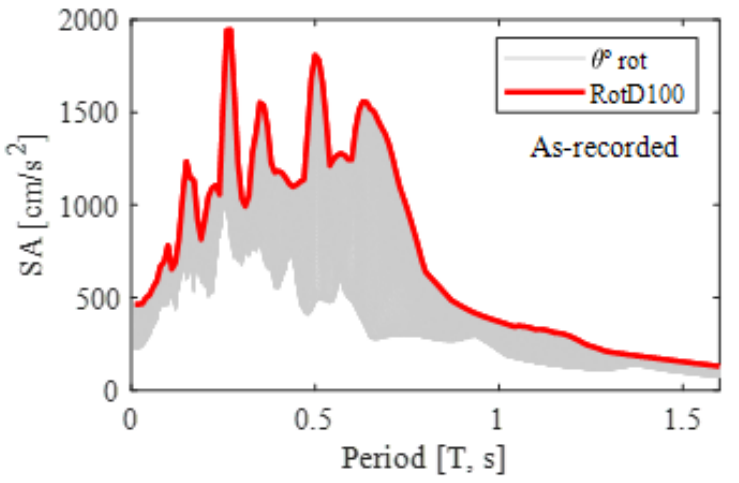

(a)

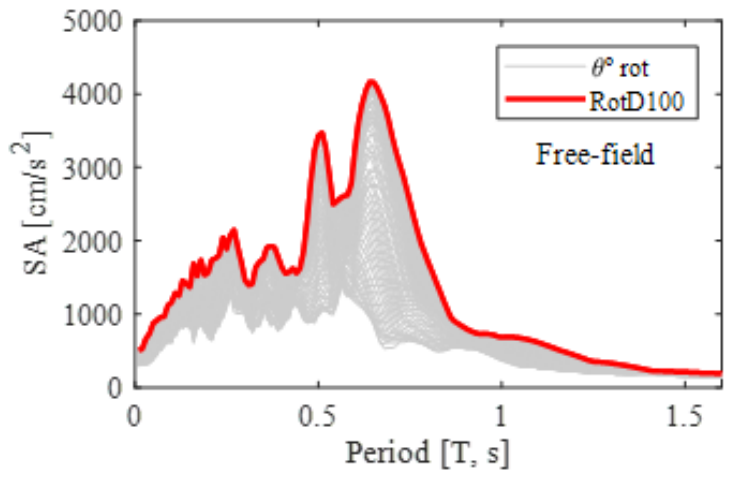

(b)

Fig. 8. Response spectra from the rotated histories and their envelope (RotD100) for the (a) recorded motion and (b) the free-field motion at the surface. 


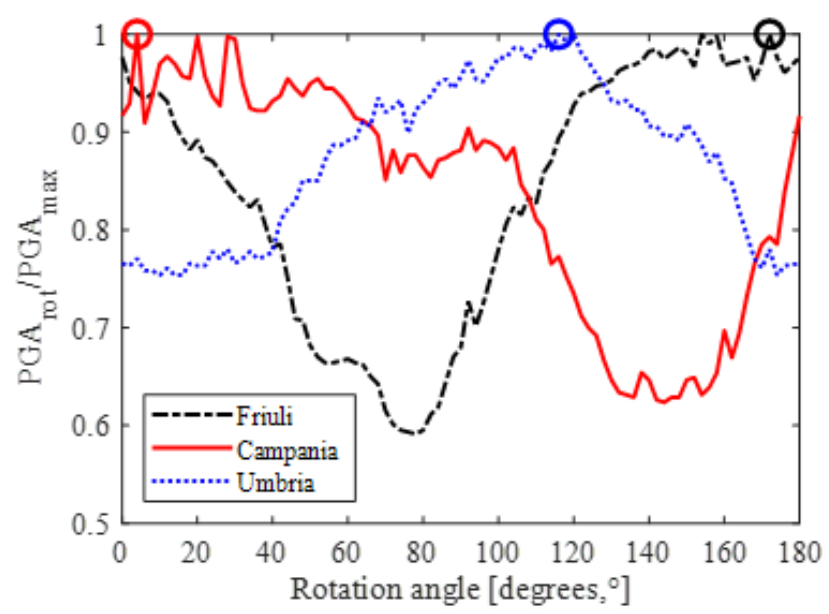

(a)

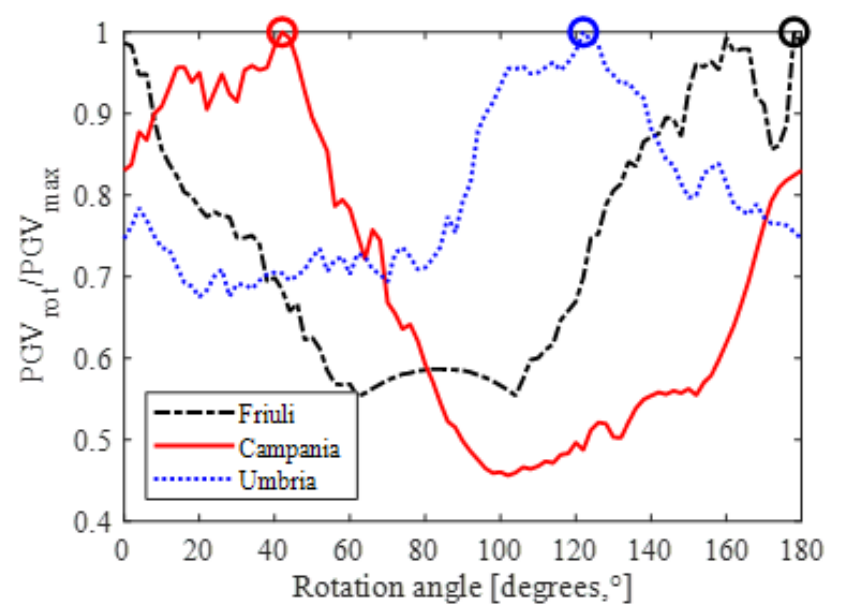

(b)

Fig. 9. Normalised (a) peak ground acceleration and (b) peak ground velocity as a function of the rotation angle for the Friuli, Campania, and Umbria seismic actions (group 1). 


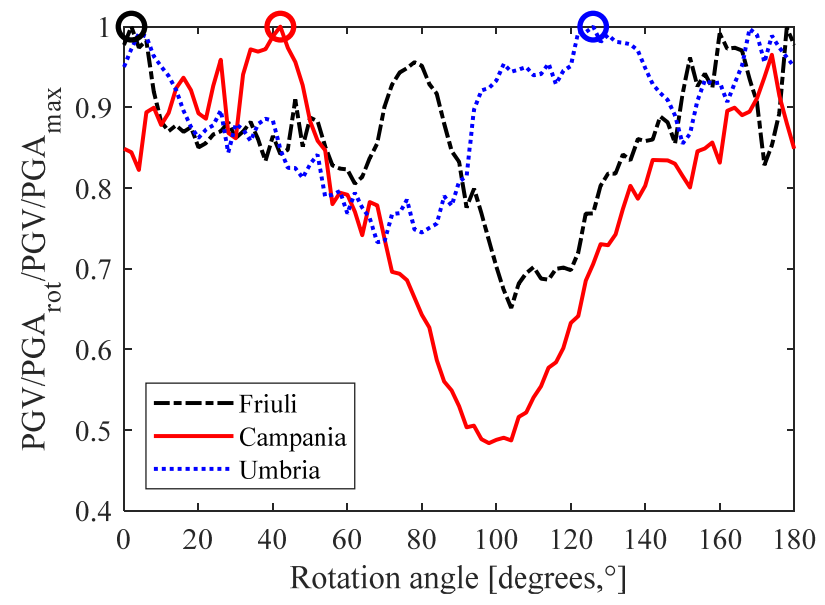

Fig. 10. Normalised PGV/PGA ratio as a function of the rotation angle for the Friuli, Campania, and Umbria seismic actions (group 1).

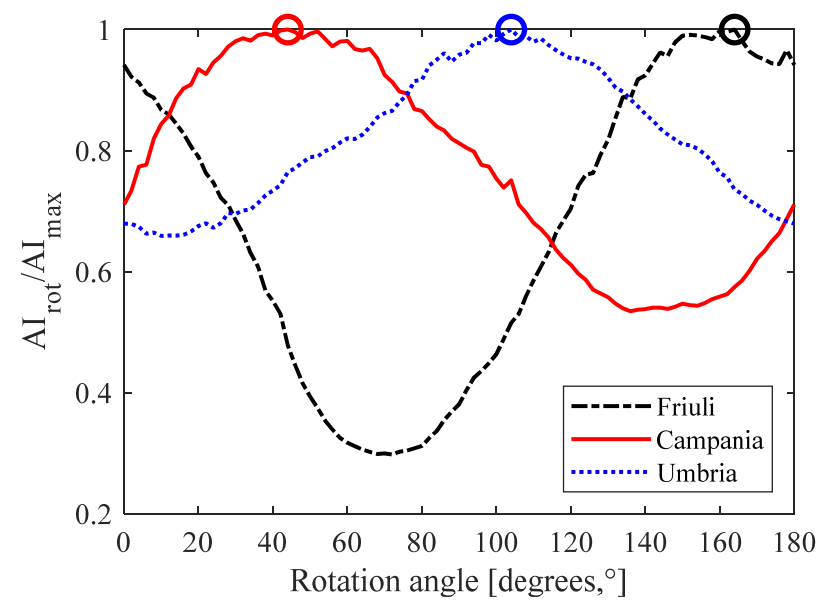

Fig. 11. Normalised Arias intensity as a function of the rotation angle for the Friuli, Campania, and Umbria seismic actions (group 1). 


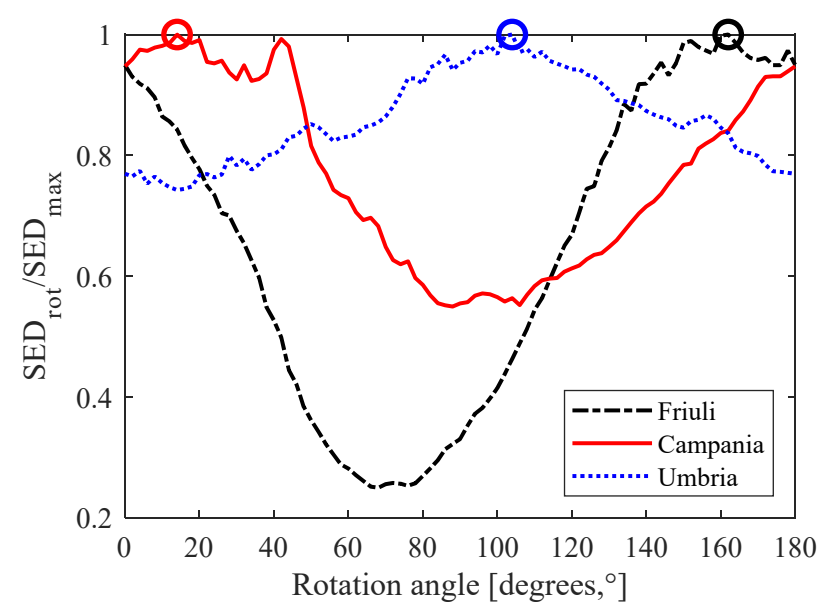

Fig. 12. Normalised specific energy density as a function of the rotation angle for the Friuli, Campania, and Umbria seismic actions (group 1).

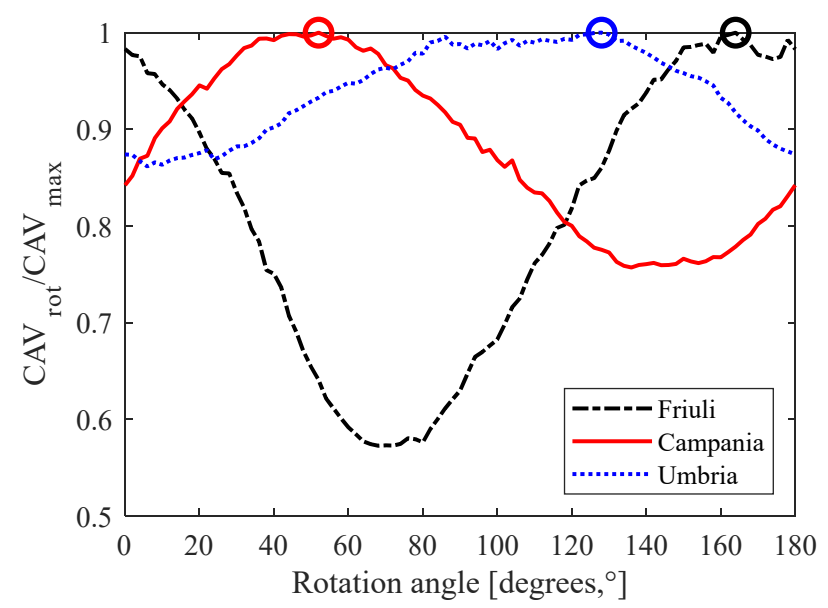

Fig. 13. Normalised cumulative absolute velocity as a function of the rotation angle for the Friuli, Campania, and Umbria seismic actions (group 1). 
(a)

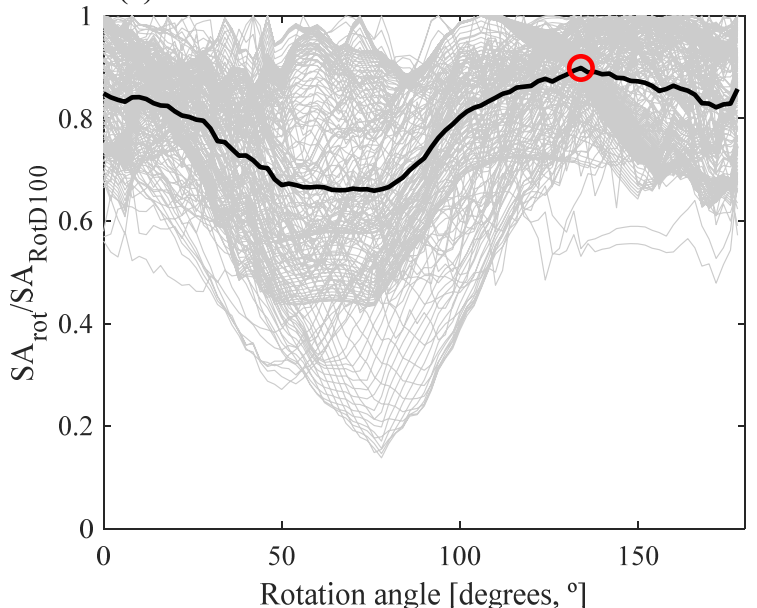

(c)

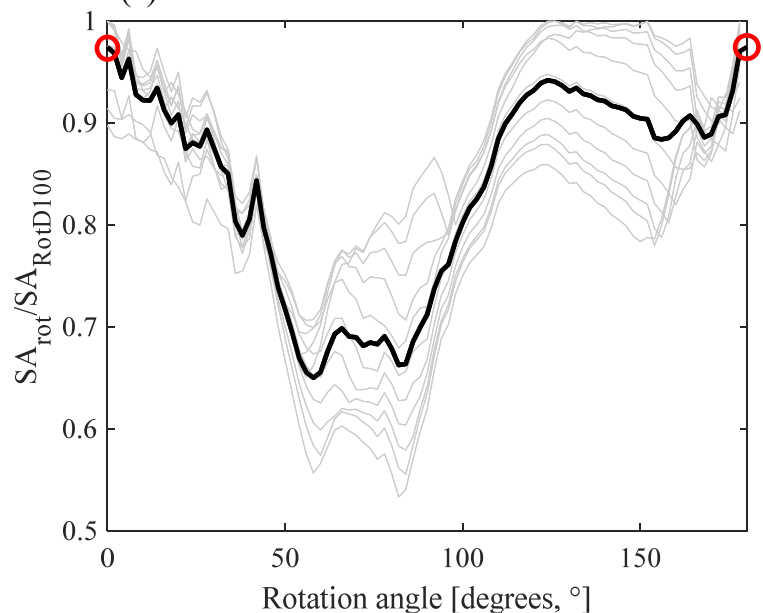

(b)

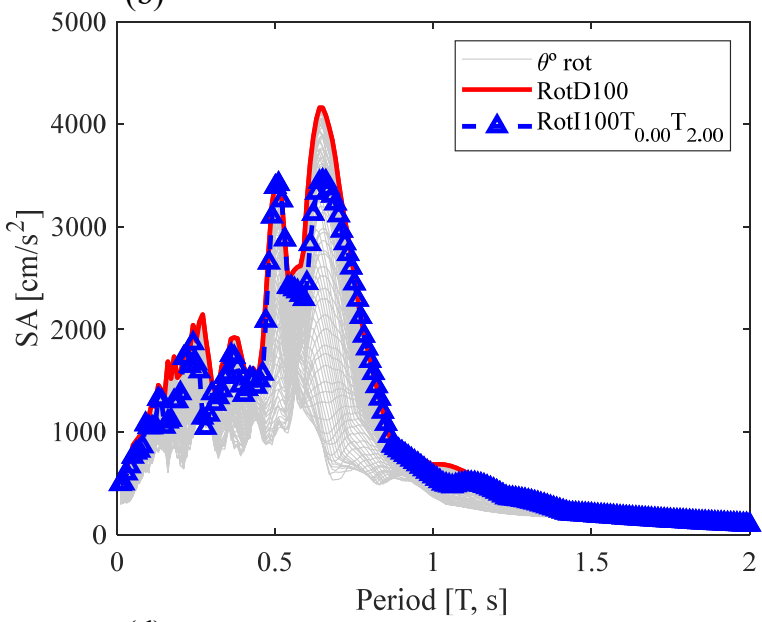

(d)

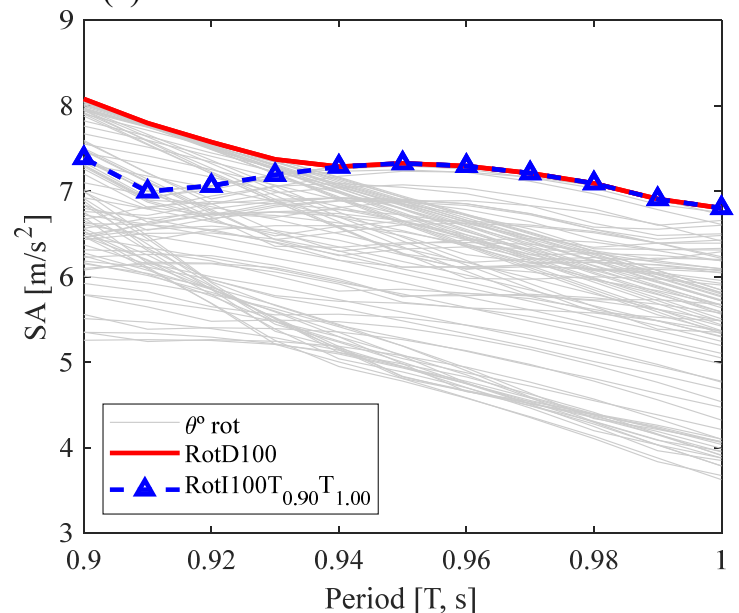

Fig. 14. SArot/SARotD100 spectral ratio as a function of the rotation angle for the Friuli earthquake for vibration periods (a) between 0.0 and $2.0 \mathrm{~s}$ and (c) between 0.9 and $1.0 \mathrm{~s}$. Response spectra from the rotated motions, the RotD100 spectrum, and the RotI100T $\mathrm{T}_{2}$ spectrum for the Friuli seismic actions for vibration periods (b) between 0.0 and $2.0 \mathrm{~s}$ and (d) between 0.9 and $1.0 \mathrm{~s}$. 


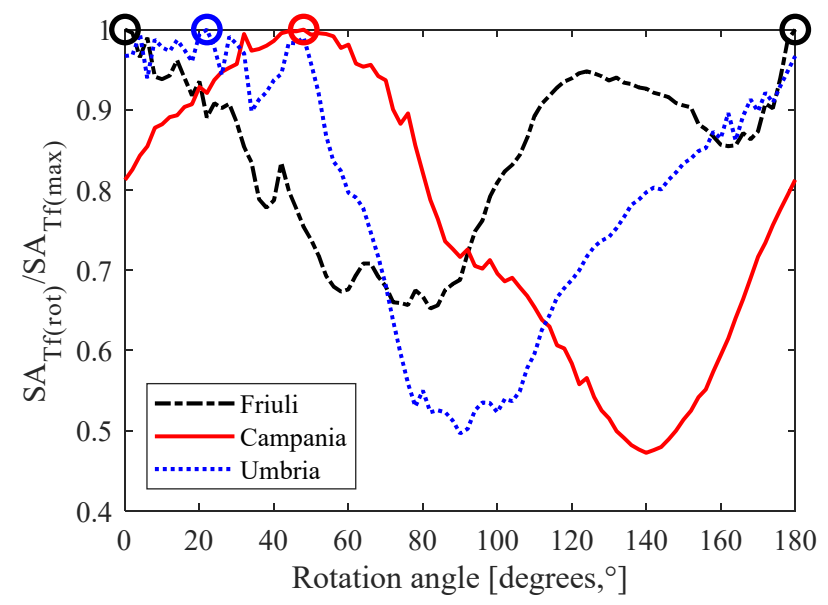

Fig. 15. Normalised spectral response for the fundamental period of the building $\left(T_{f}=0.95 \mathrm{~s}\right)$ as a function of the rotation angle for the Friuli, Campania, and Umbria seismic actions (group 1). 
(a)

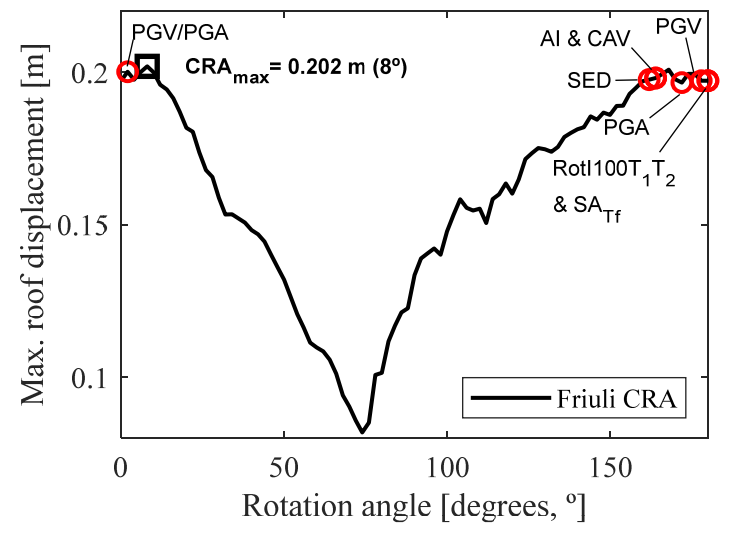

(b)

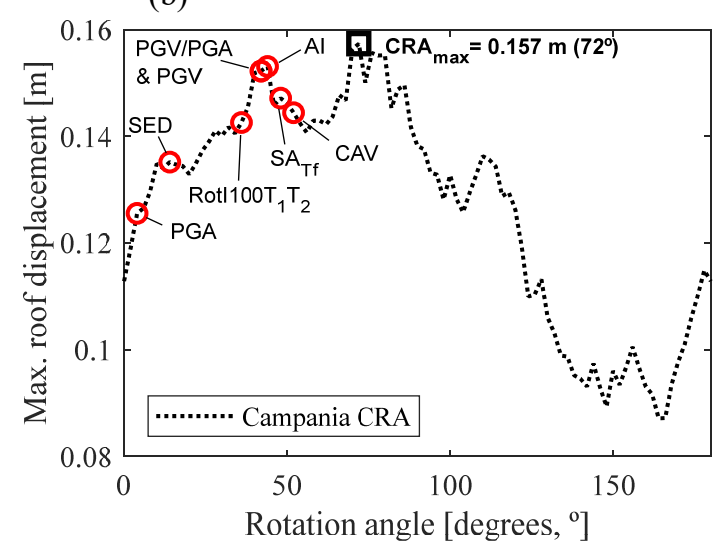

(c)

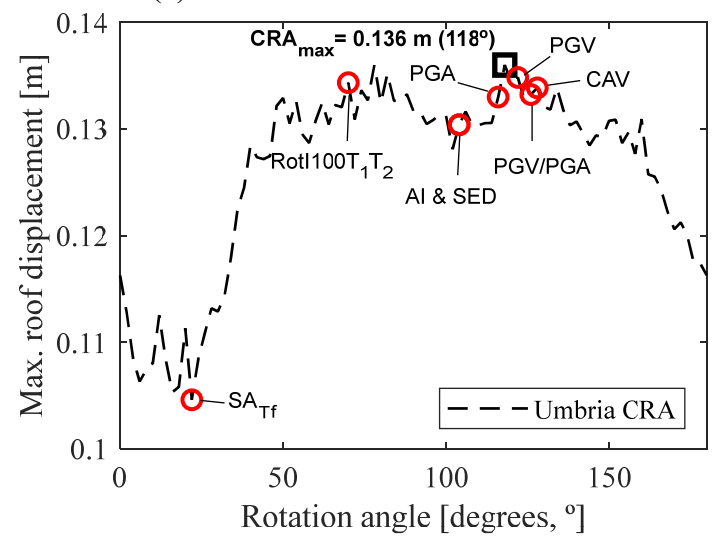

Fig. 16. Comparison between the relative roof displacements obtained from the CRA and SRA for the (a) Friuli, (b) Campania, and (c) Umbria seismic actions (group 1). 


\section{Tables}

Table 1. Cases studied.

\begin{tabular}{ccccc}
\hline Group & $\begin{array}{c}\text { Soil } \\
\text { thickness } \\
(\mathbf{m})\end{array}$ & $\begin{array}{c}\text { Seismic } \\
\text { actions }\end{array}$ & Building & $\begin{array}{c}\text { Building } \\
\text { fundamental } \\
\text { period, } \boldsymbol{T}_{\boldsymbol{f}}(\mathbf{s})\end{array}$ \\
\hline \multirow{3}{*}{$\begin{array}{c}\text { Friuli } \\
\text { Campania } \\
\text { Umbria }\end{array}$} & 4-storey & 0.95 \\
\hline \multirow{2}{*}{2} & 10 & Friuli & 4-storey & 0.95 \\
& 20 & & 3-storey & 0.80 \\
3 & 30 & & F-storey & 0.95 \\
& 30 & Friuli & 5-storey & 1.11 \\
\hline
\end{tabular}

Table 2. Soil parameters.

\begin{tabular}{|c|c|c|c|}
\hline Parameter & Symbol & Units & Value \\
\hline Unit weight & $\gamma$ & $\mathrm{kN} / \mathrm{m}^{3}$ & 20 \\
\hline Small strain shear stiffness & $G_{0}^{\text {ref }}$ & $\mathrm{kN} / \mathrm{m}^{2}$ & 125000 \\
\hline Shear strain at $0.7 G_{0}$ & $\gamma_{0.7}$ & - & $1.5 \mathrm{E}-4$ \\
\hline Triaxial compression stiffness & $E_{50}^{\mathrm{ref}}$ & $\mathrm{kN} / \mathrm{m}^{2}$ & 40000 \\
\hline Primary oedometric stiffness & $E_{\text {oed }}^{\text {ref }}$ & $\mathrm{kN} / \mathrm{m}^{2}$ & 32000 \\
\hline Unloading/reloading stiffness & $E_{\mathrm{ur}}^{\mathrm{ref}}$ & $\mathrm{kN} / \mathrm{m}^{2}$ & 120000 \\
\hline $\begin{array}{l}\text { Poisson's ratio for } \\
\text { unloading/reloading }\end{array}$ & $v_{\mathrm{ur}}$ & - & 0.2 \\
\hline Reference pressure & $p_{\text {ref }}$ & $\mathrm{kN} / \mathrm{m}^{2}$ & 100 \\
\hline Rate of stress-dependency & $m$ & - & 0.5 \\
\hline Cohesion & $c$ & $\mathrm{kN} / \mathrm{m}^{2}$ & 0 \\
\hline Friction angle & $\phi$ & $\circ$ & 35 \\
\hline Dilatancy angle & $\psi$ & $\circ$ & 5 \\
\hline Failure ratio & $R_{f}$ & - & 0.9 \\
\hline $\begin{array}{l}\text { Stress ratio for normal } \\
\text { consolidation }\end{array}$ & $K_{0}^{\mathrm{nc}}$ & - & 0.426 \\
\hline
\end{tabular}


Table 3. Critical incidence angles where the maximum relative roof displacement occurred with the CRA and the SRA.

\begin{tabular}{|c|c|c|c|c|c|c|c|c|c|c|}
\hline \multirow[b]{2}{*}{ Approach } & \multirow[b]{2}{*}{ Parameter } & \multicolumn{3}{|c|}{ Group 1} & \multicolumn{3}{|c|}{ Group 2} & \multicolumn{3}{|c|}{ Group 3} \\
\hline & & Friuli & Campania & Umbria & $10 \mathrm{~m}$ & $20 \mathrm{~m}$ & $30 \mathrm{~m}$ & $\begin{array}{c}\text { 3- } \\
\text { storey }\end{array}$ & 4-storey & $\begin{array}{c}\text { 5- } \\
\text { storey }\end{array}$ \\
\hline CRA & $\max$ & $8^{\circ}$ & $72^{\circ}$ & $118^{\circ}$ & $144^{\circ}$ & $136^{\circ}$ & $8^{\circ}$ & $132^{\circ}$ & $8^{\circ}$ & $175^{\circ}$ \\
\hline SRA with PGA & $\max$ & $172^{\circ}$ & $4^{\circ}$ & $116^{\circ}$ & $148^{\circ}$ & $164^{\circ}$ & $172^{\circ}$ & $172^{\circ}$ & $172^{\circ}$ & $172^{\circ}$ \\
\hline SRA with PGV & $\max$ & $178^{\circ}$ & $42^{\circ}$ & $122^{\circ}$ & $148^{\circ}$ & $146^{\circ}$ & $178^{\circ}$ & $178^{\circ}$ & $178^{\circ}$ & $178^{\circ}$ \\
\hline SRA with PGV/PGA & $\max$ & $2^{\circ}$ & $42^{\circ}$ & $126^{\circ}$ & $150^{\circ}$ & $146^{\circ}$ & $2^{\circ}$ & $2^{\circ}$ & $2^{\circ}$ & $2^{\circ}$ \\
\hline SRA with AI & $\max$ & $164^{\circ}$ & $44^{\circ}$ & $104^{\circ}$ & $154^{\circ}$ & $142^{\circ}$ & $164^{\circ}$ & $164^{\circ}$ & $164^{\circ}$ & $164^{\circ}$ \\
\hline SRA with SED & $\max$ & $162^{\circ}$ & $14^{\circ}$ & $104^{\circ}$ & $166^{\circ}$ & $140^{\circ}$ & $162^{\circ}$ & $162^{\circ}$ & $162^{\circ}$ & $162^{\circ}$ \\
\hline SRA with CAV & $\max$ & $164^{\circ}$ & $52^{\circ}$ & $128^{\circ}$ & $154^{\circ}$ & $142^{\circ}$ & $164^{\circ}$ & $164^{\circ}$ & $164^{\circ}$ & $164^{\circ}$ \\
\hline SRA with $\mathrm{SA}_{\mathrm{Tf}}$ & $\max$ & $0^{\circ}$ or $180^{\circ}$ & $48^{\circ}$ & $22^{\circ}$ & $36^{\circ}$ & $174^{\circ}$ & $0^{\circ}$ or $180^{\circ}$ & $142^{\circ}$ & $0^{\circ}$ or $180^{\circ}$ & $178^{\circ}$ \\
\hline $\begin{array}{l}\text { SRA with } \mathrm{SA}_{\text {rot }} / \mathrm{SA}_{\mathrm{RotD} 100} \\
\left(\mathrm{RotI}_{\left.100 \mathrm{~T}_{1} \mathrm{~T}_{2}\right)}\right.\end{array}$ & $\max$ & $0^{\circ}$ or $180^{\circ}$ & $36^{\circ}$ & $70^{\circ}$ & $154^{\circ}$ & $146^{\circ}$ & $0^{\circ}$ or $180^{\circ}$ & $134^{\circ}$ & $0^{\circ}$ or $180^{\circ}$ & $178^{\circ}$ \\
\hline
\end{tabular}

Table 4. Comparison between the relative roof displacements obtained through the CRA and SRA.

\begin{tabular}{|c|c|c|c|c|c|c|c|c|c|c|c|}
\hline \multirow{2}{*}{ Approach } & \multirow{2}{*}{ Roof displacement } & \multicolumn{3}{|c|}{ Group 1} & \multicolumn{3}{|c|}{ Group 2} & \multicolumn{3}{|c|}{ Group 3} & \multirow{2}{*}{$\begin{array}{c}\text { Mean } \\
\text { relative } \\
\text { error }(\delta \text { in } \\
\%)^{*}\end{array}$} \\
\hline & & Friuli & Campania & Umbria & $10 \mathrm{~m}$ & $20 \mathrm{~m}$ & $30 \mathrm{~m}$ & 3-storey & $\begin{array}{c}\text { 4- } \\
\text { storey }\end{array}$ & 5-storey & \\
\hline CRA & $\max .(\mathrm{m})$ & 0.202 & 0.157 & 0.136 & 0.141 & 0.158 & 0.202 & 0.123 & 0.202 & 0.180 & - \\
\hline \multirow{2}{*}{ SRA with PGA } & $\max .(\mathrm{m})$ & 0.189 & 0.126 & 0.133 & 0.141 & 0.145 & 0.189 & 0.113 & 0.189 & 0.178 & \multirow{2}{*}{-6.551} \\
\hline & $\delta$ with $\mathrm{CRA}_{\max }(\%)$ & -6.436 & -19.745 & -2.206 & 0.000 & -8.228 & -6.436 & -8.130 & -6.436 & -1.111 & \\
\hline \multirow{2}{*}{ SRA with PGV } & $\max .(\mathrm{m})$ & 0.197 & 0.152 & 0.135 & 0.141 & 0.151 & 0.197 & 0.115 & 0.197 & 0.180 & \multirow{2}{*}{-2.476} \\
\hline & $\delta$ with $\mathrm{CRA}_{\max }(\%)$ & -2.475 & -3.185 & -0.735 & 0.000 & -4.430 & -2.475 & -6.504 & -2.475 & 0.000 & \\
\hline \multirow{2}{*}{ SRA with PGV/PGA } & $\max .(\mathrm{m})$ & 0.200 & 0.152 & 0.133 & 0.140 & 0.151 & 0.200 & 0.117 & 0.200 & 0.174 & \multirow{2}{*}{-2.819} \\
\hline & $\delta$ with $\mathrm{CRA}_{\max }(\%)$ & -0.990 & -3.185 & -2.206 & -0.709 & -4.430 & -0.990 & -4.878 & -0.990 & -3.333 & \\
\hline \multirow{2}{*}{ SRA with AI } & $\max .(\mathrm{m})$ & 0.198 & 0.153 & 0.130 & 0.136 & 0.155 & 0.198 & 0.113 & 0.198 & 0.177 & \multirow{2}{*}{-3.455} \\
\hline & $\delta$ with $\mathrm{CRA}_{\max }(\%)$ & -1.980 & -2.548 & -4.412 & -3.546 & -1.899 & -1.980 & -8.130 & -1.980 & -1.667 & \\
\hline \multirow{2}{*}{ SRA with SED } & $\max .(\mathrm{m})$ & 0.198 & 0.135 & 0.130 & 0.131 & 0.156 & 0.198 & 0.107 & 0.198 & 0.175 & \multirow{2}{*}{-6.364} \\
\hline & $\delta$ with $\mathrm{CRA}_{\max }(\%)$ & -1.980 & -14.013 & -4.412 & -7.092 & -1.266 & -1.980 & -13.008 & -1.980 & -2.778 & \\
\hline \multirow{2}{*}{ SRA with CAV } & $\max .(\mathrm{m})$ & 0.198 & 0.144 & 0.134 & 0.136 & 0.155 & 0.198 & 0.113 & 0.198 & 0.177 & \multirow{2}{*}{-3.853} \\
\hline & $\delta$ with $\mathrm{CRA}_{\max }(\%)$ & -1.980 & -8.280 & -1.471 & -3.546 & -1.899 & -1.980 & -8.130 & -1.980 & -1.667 & \\
\hline \multirow{2}{*}{ SRA with $\mathrm{SA}_{\mathrm{Tf}}$} & $\max .(\mathrm{m})$ & 0.197 & 0.147 & 0.105 & 0.102 & 0.142 & 0.197 & 0.106 & 0.197 & 0.18 & \multirow{2}{*}{-11.892} \\
\hline & $\delta$ with $\mathrm{CRA}_{\max }(\%)$ & -2.475 & -6.369 & -22.794 & -27.660 & -10.127 & -2.475 & -13.821 & -2.475 & 0.000 & \\
\hline \multirow{2}{*}{$\begin{array}{l}\text { SRA with } \mathrm{SA}_{\text {rot }} / \mathrm{SA}_{\text {RotD100 }} \\
\left(\operatorname{RotI} 100 \mathrm{~T}_{1} \mathrm{~T}_{2}\right)\end{array}$} & $\max .(\mathrm{m})$ & 0.197 & 0.143 & 0.134 & 0.136 & 0.151 & 0.197 & 0.121 & 0.197 & 0.18 & \multirow{2}{*}{-3.209} \\
\hline & $\delta$ with $\mathrm{CRA}_{\max }(\%)$ & -2.475 & -8.917 & -1.471 & -3.546 & -4.430 & -2.475 & -1.626 & -2.475 & 0.000 & \\
\hline \multicolumn{2}{|c|}{ Mean relative error $(\delta$ in \%) } & -2.599 & -8.280 & -4.963 & -5.762 & -4.589 & -2.599 & -8.028 & -2.599 & -1.320 & \\
\hline
\end{tabular}

*The Friuli, the $30 \mathrm{~m}$ and the 4-storey analyses from group 1,2 and 3 respectively are the same analysis, therefore only are considered once in the mean error estimation. 
Table 5. Comparison between the relative roof displacements obtained through the CRA and the as-recorded components.

\begin{tabular}{|c|c|c|c|c|c|c|c|c|c|c|c|}
\hline \multirow{2}{*}{ Approach } & \multirow{2}{*}{ Roof displacement } & \multicolumn{3}{|c|}{ Group 1} & \multicolumn{3}{|c|}{ Group 2} & \multicolumn{3}{|c|}{ Group 3} & \multirow[t]{2}{*}{$\begin{array}{l}\text { Mean relative } \\
\text { error }(\delta \text { in \%)* }\end{array}$} \\
\hline & & Friuli & Campania & Umbria & $10 \mathrm{~m}$ & $20 \mathrm{~m}$ & $30 \mathrm{~m}$ & 3-storey & 4-storey & \begin{tabular}{|c|}
$5-$ \\
storey
\end{tabular} & \\
\hline CRA & $\max .(\mathrm{m})$ & 0.202 & 0.157 & 0.136 & 0.141 & 0.158 & 0.202 & 0.123 & 0.202 & 0.180 & - \\
\hline \multirow{4}{*}{ As-recorded (AR) } & $0^{\circ} \max .(\mathrm{m})$ & 0.197 & 0.113 & 0.116 & 0.132 & 0.139 & 0.197 & 0.115 & 0.197 & 0.176 & \multirow{2}{*}{-10.334} \\
\hline & $\delta$ with $\mathrm{CRA}_{\max }(\%)$ & -2.475 & -28.025 & -14.706 & -6.383 & -12.025 & -2.475 & -6.504 & -2.475 & -2.222 & \\
\hline & $90^{\circ} \max .(\mathrm{m})$ & 0.133 & 0.138 & 0.132 & 0.066 & 0.106 & 0.133 & 0.093 & 0.133 & 0.148 & \multirow{2}{*}{-25.353} \\
\hline & $\delta$ with $\mathrm{CRA}_{\max }(\%)$ & -34.158 & -12.102 & -2.941 & -53.191 & -32.911 & -34.158 & -24.390 & -34.158 & -17.778 & \\
\hline \multicolumn{2}{|c|}{ Mean relative error ( $\delta$ in \%) } & -18.317 & -20.064 & -8.824 & -29.787 & -22.468 & -18.317 & -15.447 & -18.317 & -10.000 & \\
\hline
\end{tabular}

*The Friuli and the $30 \mathrm{~m}$ and the 4-storey analyses from group 1,2 and 3 respectively are the same analysis, therefore only are considered once in the mean error estimation. 